\title{
La aplicación de la Ley Andaluza de transparencia en las entidades locales
}

\author{
Emilio Guichot
}

Catedrático acreditado de Derecho Administrativo

Universidad de Sevilla

SUMARIO: I.- EL SENTIDO DE LA TRANSPARENCIA, SU RECONOGIMIENTO EN LA CONSTITUGIÓN Y SU DESARROLLO LEGAL ANTERIOR A LAS LEYES ESTATAL Y ANDALUZA DE TRANSPARENCIA. II.- LA APROBACIÓN DE LAS LEYES ESTATAL Y ANDALUZA DE TRANSPARENCIA. SU RESPECTIVO ÁMBITO DE APLICACIÓN. EL ÁMBITO DE DECISIÓN DE LAS ENTIDADES LOCALES. LA ORDENANZA TIPO DE LA FEMP. III.- OBLIGADOS. IV.- PRINGIPIOS BÁSICOS, DERECHOS Y OBLIGACIONES. V.- LÍMITES A LA TRANSPARENCIA Y EL AGGESO A LA INFORMAGIÓN.VI.- PUBLICIDAD ACTIVA. VII.DERECHO DE ACGESO A LA INFORMAGIÓN PÚBLICA O PUBLICIDAD PASIVA. VIII.- FOMENTO DE LA TRANSPARENCIA, ORGANIZAGIÓN Y CONTROL. EL CONSEJO DE TRANSPARENGIA Y PROTEGGIÓN DE DATOS DE ANDALUCÍA. 1. Fomento. 2. Organización. 3. Control. IX. RÉGIMEN SANCIONADOR. X.- LA RELACIÓN DE LAS LEYES DE TRANSPARENCIA CON OTRAS NORMAS QUE REGULAN EL ACGESO A LA INFORMACIÓN. EN PARTICULAR, EL ACGESO POR LOS CONCEJALES A LA INFORMACIÓN MUNICIPAL. 1. La relación con otros bloques normativos: acceso a documentos de procedimientos en curso, normativas especiales y legislación sobre archivos. 2. En particular, el acceso por los concejales a la información municipal.

\section{RESUMEN}

En este trabajo se trata la aplicación de las recientes Leyes de transparencia estatal y andaluza a las entidades locales de Andalucía. La Ley estatal de 2013 y la Ley andaluza de 2014 entrarán en vigor en diciembre de 2015 para las entidades locales. Hasta esa fecha, las entidades locales tienen delante de sí un auténtico reto de ordenar la información, crear portales de transparencia, por sí mismas o en colaboración entre sí, con las Diputaciones y con los órganos de la Comunidad autónoma, desig- 
nar a las autoridades y órganos competentes, formarlos y acercar el contenido de la ley a la ciudadanía. En este trabajo se abordan las cuestiones jurídicas que todo ello suscita.

\section{PALABRAS CLAVE}

Transparencia, acceso a la información, entidades locales

\section{ABSTRACT}

This paper analyses recent state and regional transparency laws and their application to local entities. State transparency law (2013) and Andalusian transparency law (2014) will come into force to local authorities in December 2015. Until then, local authorities have to face the challenge of organizing the information they hold, creating transparency webs, by themselves or in collaboration with other local authorities and with the regional public administration, designating the authorities and public servants who will be competent to apply the law, training them and helping people to exercise their right.

\section{KEY WORDS}

Transparency, access to public information, local entities

\section{EL SENTIDO DE LA TRANSPARENCIA, SU REGONOCI- MIENTO EN LA CONSTITUCIÓN Y SU DESARROLLO LE- GAL ANTERIOR A LAS LEYES ESTATAL Y ANDALUZA DE TRANSPARENCIA}

La circulación y contraste de la información sobre la organización, la actividad o el gasto público es necesaria para la creación de una opinión pública que pueda decidir su propio destino como sociedad, controlando la actuación del poder y participando activamente en su ejercicio. Estos son los presupuestos que han llevado a una práctica generalización en la aprobación de leyes de acceso a la información pública a nivel mundial, en la que los países más desarrollados económica y socialmente han actuado como pioneros ${ }^{1}$.

\footnotetext{
${ }^{1}$ Permítaseme la remisión a mis trabajos "Derecho de acceso a la información: experiencias regionales y estatales en Europa y América”, Derecho comparado de la Información, México D. F., núm. 19, 2012, pp. 135-188, "El nuevo Derecho europeo de acceso a la información", Revista de Administración Pública, 2003, núm. 160, pp. 283-316 y Transparencia y acceso a la información en el Derecho europeo, Ed. Derecho Global, Sevilla, 2011, y a la bibliografía en ellos citada.
} 
Hasta la aprobación de la LTBG, el derecho de acceso a la información pública, previsto en el art. 105.b) de la Constitución, había estado desarrollado con carácter general en el art. 37 de la Ley 30/1992, de 26 de noviembre, de Régimen Jurídico de las Administraciones Públicas y del Procedimiento Administrativo Común (LRJPAC), cuyas deficiencias y lagunas -incluida la falta de regulación del procedimiento y de previsión de un órgano independiente de control- eran ostensibles ${ }^{2}$. Además, se habían aprobado, transponiendo sendas Directivas europeas, la Ley 27/2006, de 18 de julio, que regula entre otros el acceso a la información ambiental, y la Ley $37 / 2007$, de 16 de noviembre, sobre reutilización de la información del sector público. A todo ello se unía normativa sectorial (contratos, subvenciones, función pública, actividades y bienes de altos cargos, entre otras) que prevé obligaciones específicas de publicidad. Lo que faltaba era, pues, una regulación básica e integral.

En la esfera local, la LBRL regula en el Capítulo IV de su Título V la "información y participación ciudadana", y establece toda una serie de medidas de publicidad $^{3}$.

2 ÁLVAREZ RICO, M., "El derecho de acceso a los documentos administrativos", Documentación Administrativa, núm. 183, 1979, pp. 103-133; FERNÁNDEZ RAMOS, S., El derecho de acceso a los documentos administrativos, Marcial Pons, Madrid, 1997; MESTRE DELGADO, J. F., El derecho de acceso a archivos y registros administrativos, Givitas, Madrid, 1993; POMED SÁNCHEZ, L. A., El acceso de los ciudadanos a los archivos y registros administrativos, INAP, Madrid, 1989; RAMS RAMOS, L., Derecho de acceso a archivos y registros administrativos, Ed. Reus, Barcelona, 2009, VILLAVERDE MENÉNDEZ, Los derechos del público, Tecnos, Madrid, 1995.

${ }^{3}$ Alude a: a) la obligación de las Corporaciones Locales de facilitar la más amplia información sobre su actividad y la participación de todos los ciudadanos en la vida local (art. 69); b) la publicidad de las sesiones del pleno de las corporaciones locales (cuyas convocatorias y ordenes del día deben transmitirse a los medios de comunicación social de la localidad y publicarse en el tablón de anuncios de las Corporaciones, art. 229.1 ROF, y notificarse a las asociaciones vecinales registradas, cuando así lo soliciten expresamente y en el orden del día figuren cuestiones relacionadas con el objeto social de la entidad, art. 234.a) ROF). Además, el art. 88.2 ROF alude a la posibilidad de retransmisión en audio o video por iniciativa de la Corporación, si bien la grabación en audio o video por los asistentes depende de lo que disponga el Reglamento orgánico o, en su defecto, de la decisión del Alcalde o Presidente (algo que como veremos cambiará cuando entre en vigor la Ley de Transparencia de Andalucía). Pueden ser secretos el debate y votación de aquellos asuntos que puedan afectar al derecho fundamental a la intimidad, al honor y a la propia imagen de los ciudadanos cuando así se acuerde por mayoría absoluta (art. 70.1). Las sesiones de la Junta de Gobierno Local, por el contrario, no son públicas pero sí lo son las decisiones relativas a las atribuciones delegadas por el pleno (STG de 26 de septiembre de 2013). En todo caso, sí son públicos sus acuerdos, según el 229.2 ROF. En el caso de los municipios de gran población se dispone expresamente que sus sesiones sean secretas; c) la publicidad (mediante publicación o notificación) de los acuerdos de las corporaciones locales, en la forma prevista por la ley. Las ordenanzas, el articulado de las normas de 
A todo esto ha de unirse que en Andalucía, la LAULA, en su art. 54, previó ya en 2010 que para garantizar a la ciudadanía el acceso a la información sobre la actuación municipal, su transparencia y control democrático, así como facilitar la información intergubernamental, los ayuntamientos y sus organismos y entidades dependientes o vinculadas deben publicar en la sede electrónica de su titularidad o, en su defecto, en la sede electrónica de la respectiva Diputación provincial, en el plazo de cinco dias desde su adopción, las disposiciones y actos administrativos generales que versen sobre toda una serie de materias de la máxima relevancia ${ }^{4}$.

los planes urbanísticos y los acuerdos correspondientes a éstos cuya aprobación definitiva sea competencia de los entes locales, se publican en el Boletín Oficial de la Provincia, y las que tienen competencias urbanísticas deben tener a disposición de los ciudadanos que lo soliciten copias completas del planeamiento vigente en su ámbito territorial (art. 70.2 LBRL). Además, deberán tener a su disposición los documentos de gestión y los convenios urbanísticos y publicarán por medios telemáticos el contenido actualizado de los instrumentos de ordenación territorial y urbanística en vigor, el anuncio de su sometimiento a información pública y cualquier acto de tramitación que sea relevante para su aprobación o alteración. En los municipios menores de 5.000 habitantes, esta publicación podrá realizarse a través de los entes supramunicipales que tengan atribuida la función de asistencia y cooperación técnica con ellos, que deberán prestarles dicha cooperación. Cuando una alteración de la ordenación urbanística, que no se efectúe en el marco de un ejercicio pleno de la potestad de ordenación, incremente la edificabilidad o la densidad o modifique los usos del suelo, deberá hacerse constar en el expediente la identidad de todos los propietarios o titulares de otros derechos reales sobre las fincas afectadas durante los cinco años anteriores a su iniciación, según conste en el registro o instrumento utilizado a efectos de notificaciones a los interesados de conformidad con la legislación en la materia (art. 70 ter LBRL). Además, en materia organizativa y retributiva, se prevé la publicidad de los acuerdos plenarios referentes a retribuciones de los cargos con dedicación exclusiva y parcial y el régimen de dedicación de estos últimos, indemnizaciones y asistencias y acuerdos del presidente de la Corporación determinando los miembros de la misma que realicen funciones en régimen de dedicación exclusiva o parcial, la de las declaraciones anuales de bienes y actividades, la de instrumentos de ordenación y estructuración de los recursos humanos, relaciones de puestos de trabajo, plantilla, oferta de empleo público, convocatoria y base de los procesos selectivos, perfil del contratante, convocatoria y bases de las subvenciones, presupuestos generales y demás documentación económico-financiera y, recientemente, en la Ley 27/2013, de 27 de diciembre, de racionalización y sostenibilidad de la Administración Local (LRSAL) la publicidad de la masa salarial del personal laboral del sector público local y semestral del número de personal eventual. Sobre el tema, véase, por todos, FERNÁNDEZ RAMOS, S., La información y participación ciudadana en la Administración local, Bosch, Barcelona, 2005 y JIMÉNEZ PLAZA. I., El derecho de acceso a la información municipal, Iustel, Madrid, 2006, y la bibliografía allí citada.

${ }^{4}$ Son las siguientes: a) ordenación territorial, ordenación y disciplina urbanísticas, y proyectos para su ejecución; b) planificación, programación y gestión de viviendas; c) ordenación y prestación de servicios básicos; d) prestación de servicios sociales comunitarios y de otros servicios locales de interés general; e) organización municipal complementaria; f) seguridad en lugares públicos; g) defensa de las personas consumidoras y usuarias; h) salud pública; i) patrimonio de las entidades 
En definitiva, son las entidades locales las sometidas, con mucho, a una mayor exigencia de publicidad que, puede decirse, que, en Andalucía, afecta ya prácticamente al conjunto de su actividad.

Junto a esta densa malla normativa, hay que resaltar la falta de un desarrollo digno de tal nombre de lo previsto en el art. 70.3 LBRL según el cual: "Todos los ciudadanos tienen derecho a obtener copias y certificaciones acreditativas de los acuerdos de las corporaciones locales y sus antecedentes, así como a consultar los archivos y registros en los términos que disponga la legislación de desarrollo del art. 105, párrafo b) de la Constitución. La denegación o limitación de este derecho, en todo cuanto afecte a la seguridad y defensa del Estado, la averiguación de los delitos o la intimidad de las personas, deberá verificarse mediante resolución motivada". De nuevo, es esa legislación completa y general de desarrollo del derecho de acceso de los ciudadanos a la información la que faltaba también para el ámbito local.

El objeto de este trabajo es precisamente la aplicación de las normas estatal y andaluza sobre transparencia recientemente aprobadas a las entidades locales ${ }^{5}$.

\section{LA APROBACIÓN DE LAS LEYES ESTATAL Y ANDALUZA DE TRANSPARENGIA. SU RESPECTIVO ÁMBITO DE APLI- GACIÓN. EL ÁMBITO DE DEGISIÓN DE LAS ENTIDADES LOCALES. LA ORDENANZA TIPO DE LA FEMP}

Los impulsos de la sociedad (ciudadanos en general, organizaciones no gubernamentales, periodistas, académicos) en tiempos de una profunda crisis de confianza política, institucional y económica colocaron la transparencia en la agenda política de forma no sólo nominal sino efectiva, de forma muy notoria a partir del año 2011,

locales, incluyendo las que afecten a los bienes integrantes del Patrimonio Histórico Andaluz; j) actividad económico-financiera; k) aprobación, ejecución y liquidación del presupuesto de la entidad, aši como las modificaciones presupuestarias; l) selección, promoción y regulación de las condiciones de trabajo del personal funcionario y laboral de las entidades locales; m) contratación administrativa; n) medio ambiente, cuando afecten a los derechos reconocidos por la normativa reguladora del acceso a la información, de participación pública y de acceso a la justicia en materia de medio ambiente.

${ }^{5}$ Recientemente sobre este tema, en general, en el ámbito estatal, véase CAMPOS ACUÑA, M. C., "Las entidades locales ante las obligaciones de transparencia. Una primera aproximación a la Ley 19/2013, de transparencia, acceso a la información pública y buen gobierno", Revista digital CEMCI, número 23. 
en que, fruto de esos impulsos, la aprobación de una Ley de Transparencia figuró ya en todos los programas políticos de los partidos de ámbito nacional que obtuvieron representación parlamentaria, asociado al debate sobre la corrupción y la necesidad de una regeneración democrática y, tras una larga tramitación derivada sobre todo de la comparecencia de expertos en el Congreso de los Diputados, acompañada de un intenso debate ciudadano ${ }^{6}$, mediático ${ }^{7}$ y académico ${ }^{8}$, se aprobó, con importantes

${ }^{6} \mathrm{El}$ Anteproyecto se sometió a un novedoso procedimiento de consulta pública entre los días 26 de marzo y 10 de abril, cuyas aportaciones no recibieron publicidad. Se formularon críticas desde diversos sectores a la falta de publicación de las sugerencias y opiniones de los ciudadanos. Posteriormente, el Grupo Parlamentario Socialista pidió acceso a las aportaciones ciudadanas antes de presentar las enmiendas. El Gobierno le remitió un denominado "Informe sobre la consulta pública electrónica del Anteproyecto de Ley de Transparencia, Acceso a la Información Pública y Buen Gobierno (puede consultarse en: http://www.access-info.org/documents/105482716-Informe-delMinisterio-de-Presidencia.pdf). En él se informa de que la página web www.leydetransparencia.gob.es tuvo un total de 78.107 visitas y se recibieron un total de 3.669 observaciones a través de ella y otras 14 por registro. El perfil de los participantes en la consulta fue diverso: junto a ciudadanos individuales participaron Administraciones Públicas, asociaciones profesionales, organizaciones activas en materia de transparencia y otros colectivos. Requerido acceso a los originales, la Secretaría de Estado de Relaciones con las Cortes sugirió que la consulta se hiciera in situ, por el supuesto riesgo a una vulneración del derecho a la protección de datos que podría generar de lo contrario su remisión. Una parte importante de las sugerencias, que después serían también formuladas por los expertos, fueron acogidas, bien en el Proyecto, bien vía enmiendas en el Congreso de los Diputados. Es el caso de la ampliación del ámbito de sujetos obligados, sobre forma y extensión de la publicidad activa y de sanción en caso de incumplimiento, sobre no exclusión a priori de ninguna materia del concepto de información pública, sobre ponderación de los límites al derecho de acceso, sobre la vía telemática como la vía por defecto para transmitir la información o sobre la inconveniencia de otorgar la competencia de control a la Agencia Estatal de Evaluación de las Políticas Públicas y Calidad de los Servicios. No se acogieron, sin embargo, la propuesta de reconocimiento del derecho de acceso como derecho fundamental (y tramitación consiguiente como ley orgánica) ni la mayor concreción de los límites al derecho de acceso o la previsión de un mecanismo de silencio positivo y no negativo.

${ }^{7}$ Por todos, entre los artículos de expertos en la materia, A. GARRIGUES WALKER, J. LIZCANO ÁLVAREZ, J. SÁNCHEZ LAMBÁS y M. VILLORIA MENDIETA (integrantes del Comité de Dirección de Transparencia Internacional España) en el diario EL PAIS, bajo el título "La Ley de Transparencia, solo el primer paso", el 5 de abril de 2012 (http://elpais.com/elpais/2012/03/29/opinion/1333034562_798871.html), o E. GUICHOT, en el diario ABC, con el título "Transparencia: la hora de la verdad", el 30 de abril de 2012 (http://www.abc.es/historicoopinion/index.asp?ff $=20120430 \& i d n=1502732850340$ ).

${ }^{8}$ Vid. GUICHOT, E., "El Anteproyecto de Ley de Transparencia”, El Cronista del Estado Social y Democrático de Derecho, núm. 30, junio 2012, pp. 28-40, y "El proyecto de Ley de Transparencia y acceso a la información pública y el margen de actuación de las Comunidades Autónomas", Revista Andaluza de Administración Pública, núm. 84, 2012, pp. 89-134; BARRERO RODRÍGUEZ, G., "La 
modificaciones en los sujetos obligados y en la institución independiente de garantía, la Ley 19/2013, de 9 de diciembre, de transparencia, acceso a la información pública y buen gobierno, $\mathrm{LTBG}^{9}$.

Su disposición final séptima prevé la entrada en vigor de la LTBG al año de su publicación, en el ámbito estatal (esto es, el 10 de diciembre de 2014), mientras que los órganos de las Comunidades Autónomas y Entidades Locales disponen de un plazo máximo de dos años para adaptarse a sus obligaciones (es decir, el 10 de diciembre de 2015).

Las Comunidades Autónomas y las Entidades Locales estuvieron al margen del proceso de elaboración de la LTBG pero están llamadas a desarrollarla y aplicarla, pues sus instituciones y sujetos vinculados a ellas figuran entre los obligados en los mismos términos que sus equivalentes de ámbito estatal, como veremos. La LTBG ha hecho un entendimiento muy amplio de la competencia para establecer las bases del régimen jurídico de las Administraciones públicas, de modo que casi toda la regulación tiene carácter básico, incluidas las disposiciones sobre procedimiento. El ámbito propio que ha quedado para las leyes autonómicas está en la ampliación de las materias sujetas a publicidad activa y la determinación de los medios para llevarla a cabo, en las disposiciones de organización y en las medidas para garantizar la eficacia del derecho (formación del personal, elaboración de guías ciudadanas, etc.) y en la creación de autoridades independientes de transparencia o la atribución de sus competencias a autoridades independientes ya existentes. Junto a ello, cabe plantear que el plazo, establecido en un mes con carácter básico, puede ser acortado. No puede decirse lo mismo respecto de las limitaciones o del sentido del silencio, que constituyen una pieza clave en la delimitación del alcance del derecho y sus relaciones con otros bienes públicos y privados en concurrencia ${ }^{10}$.

disposición adicional $1.3^{\circ}$ del Proyecto de Ley de Transparencia, acceso a la información y buen gobierno y sus negativos efectos en el ámbito de aplicación del derecho de acceso a la información", Revista Española de Derecho Administrativo, núm. 158, 2013, pp. 221-246; FERNÁNDEZ RAMOS, S., "El acceso a la información en el Proyecto de Ley de Transparencia, acceso a la información y buen gobierno", Revista Aragonesa de Administración Pública, 2013, pp. 233-298.

${ }^{9}$ Sobre el tema, véase GUICHOT, E., "El sentido, el contexto y la tramitación de la Ley de transparencia, acceso a la información pública y buen gobierno", en GUICHOT. E. (coord.), Transparencia, Acceso a la Información Pública y Buen Gobierno. Estudio de la Ley 19/2013, de 9 de diciembre, Ed. Tecnos, Madrid, 2014, pp. 17-34.

${ }^{10}$ Sobre la extensión de las bases estatales y el margen de actuación de las leyes autonómicas, véase GUICHOT, E., "El Proyecto de Ley de transparencia y acceso a la información pública y el margen de actuación de las Comunidades Autónomas", Revista Andaluza de Administración Pública, núm. 84, 2012, pp. 89-134. Ya aprobada la Ley en GUICHOT, E., "Transparencia: aspectos generales", en GUICHOT, E. (coord.), Transparencia..., op. cit., pp. 47-50. 
El retraso en la aprobación de la Ley estatal sobre Transparencia y Acceso a la Información hizo que diversas Comunidades Autónomas tomaran la delantera, aprobando sus propias leyes sobre la materia. Es el caso de la Galicia (Ley 4/2006, de 30 de julio, de transparencia y buenas prácticas en la Administración pública gallega), Navarra (Ley Foral 11/2012, de 21 de junio, de Transparencia y del Gobierno Abierto) o Extremadura (Ley 4/2013, de 21 de mayo, de Gobierno Abierto). Otras se han aprobado con posterioridad, la primera de ellas la Ley 1/2014, de 24 de junio, de Transparencia Pública de Andalucía, LTA, que entrará en vigor al año de su publicación, esto es, el 25 de junio de 2015, para la Administración autonómica y el 10 de diciembre de 2015 para la local, junto a la Ley estatal. Le ha seguido la Ley 3/2014, de 11 de septiembre, de Transparencia y Buen Gobierno de la Rioja. A la fecha de entrega de este trabajo están en marcha otras iniciativas en diversos parlamentos autonómicos (Cataluña, País Vasco, Canarias, Asturias) y los Gobiernos de otras Comunidades Autónomas están elaborando proyectos de leyes (Valencia, Murcia, Castilla-León, Castilla-La Mancha).

Estas leyes dejan aún un margen de autonomía a las entidades locales que, básicamente, pueden ampliar aún más las materias objeto de publicidad activa, deben diseñar sus portales de transparencia y tomar decisiones en cuanto a la organización interna que permitan llevar a efecto las determinaciones en materia de transparencia, y, si quieren, acortar más aún el plazo de respuesta a las solicitudes de acceso a la información. Al respecto, hay que destacar que la Junta de Gobierno de la Federación Española de Municipios y Provincias, FEMP, aprobó el 27 de mayo de 2014 una Ordenanza Tipo de transparencia, acceso a la información y reutilización que, basada en buena medida en experiencias pioneras de algunos municipios, ofrece un modelo que puede inspirar a las ordenanzas locales que pueda aprobar cada entidad. No obstante, conviene advertir de que la Ley Andaluza, combinada con las obligaciones de publicidad ya contenidas en la LAULA, establece un trenzado normativo ya muy espeso respecto del cual la Ordenanza no supone una gran aportación. Dicho de otra forma, las entidades locales pueden (y deben) aplicar la LTA sin necesidad de aprobar sus propias ordenanzas, al margen de que puedan hacerlo para regular, sobre todo, el aspecto organizativo.

\section{OBLIGADOS}

Un primer aspecto a considerar es el de los sujetos obligados ${ }^{11}$. Los arts. 2 LTBG y 3 LTA regulan el llamado "ámbito subjetivo de aplicación". El art. 2 LTBG procede a

\footnotetext{
${ }^{11}$ Sobre el particular, véase BARRERO RODRÍGUEZ, G., "Transparencia. Ámbito subjetivo", en GUICHOT, E. (coord.), Transparencia..., op. cit., pp. 63-96; FERNÁNDEZ RAMOS, S., "El ámbito subjetivo de la normativa sobre transparencia del sector público. Problemas y disfunciones",
} 
una delimitación amplia de los sujetos obligados, que no solo comprende a Administraciones Públicas (así también, instituciones constitucionales y estatutarias o colegios profesionales o cámaras, en relación con sus actividades sujetas al Derecho administrativo). Esta delimitación ha sido retomada por el art. 3 LTA y adaptada a la tipología de entidades establecida en la normativa autonómica. En consecuencia, en lo que hace al nivel local, el "ámbito subjetivo de aplicación” es el siguiente:

a) Las entidades que integran la Administración local andaluza.

b) Los entes instrumentales de derecho público vinculados o dependientes de las administraciones locales andaluzas y, en particular, las agencias públicas administrativas locales, las agencias públicas empresariales locales y las agencias locales de régimen especial.

c) Cualesquiera otras entidades de derecho público con personalidad jurídica vinculadas a las administraciones locales andaluzas o dependientes de ellas.

d) Las sociedades mercantiles en cuyo capital social la participación, directa o indirecta, de las entidades anteriormente citadas sea superior al 50 por 100, cualquiera que sea su objeto social, incluso si es una actividad puramente industrial y mercantil en régimen de libre competencia. En todo caso, las sociedades mercantiles locales y las sociedades interlocales del art. 40 LAULA.

e) Las fundaciones del sector público previstas en la legislación de fundaciones dependientes de las entidades antes citadas. En todo caso, las fundaciones públicas locales del art. 40 LAULA.

f) Las asociaciones constituidas por las Administraciones, organismos y entidades antes relacionadas.

Junto a estas entidades se encuentran otras sobre las que pesa una "obligación de suministrar información" (arts. 4 LTBG y 4 LTA). Se trata de las personas físicas y jurídicas distintas de las referidas que presten servicios públicos o ejerzan funciones delegadas de control y otro tipo de funciones administrativas, que están obligadas a suministrar a la Administración, organismo o entidad de las anteriormente citadas a las que se encuentren vinculadas, la información que les sea solicitada para cumplir con las obligaciones previstas en la Ley, previo requerimiento y en un plazo de quince días, "sin perjuicio de los plazos que puedan establecer las entidades locales en ejerci-

en VALERO TORRIJOS, J. y FERNÁNDEZ SALMERÓN, M., Régimen jurídico de la transparencia del sector público..., op. cit., pp. 105-134 y en FERNÁNDEZ RAMOS, S., Transparencia, Acceso a la Información y Buen Gobierno. Ley 19/2013, de 9 de diciembre, Aranzadi, Cizur Menor, 2014, pp. 71-99, o SENDÍN GARCÍA, M., en RODRÍGUEZ-ARANA MUÑOZ, J. y SENDÍAN GARCÍA, M. A., Transparencia, acceso a la información y buen gobierno. Comentarios a la Ley 19/2013, de 9 de diciembre, de Transparencia, Acceso a la Información Pública y Buen Gobierno, Comares, Granada, 2014, pp. 117-129. 
cio de su autonomía" (precisiones éstas de la LTA respecto a la ausencia de plazo en la legislación estatal). De este modo, la LTBG ha optado por una solución singular respecto a la mayoría de los Derechos de nuestro entorno, en los que, cuando las leyes de acceso a la información alcanzan a estos sujetos, lo hacen por lo común en los mismos términos que a los demás, esto es, imponiéndoles la obligación de informar directamente a los ciudadanos. En todo caso, puede ser una solución acertada en la medida en que cara al ciudadano es la Administración la titular del servicio o de la función administrativa, por lo que resulta pertinente que la exigencia de información se dirija a ésta. Además, este mecanismo de flujo de información a petición del ciudadano puede facilitar el control real por la Administración del desempeño de la actividad. Por lo demás, parece evidente que la información a facilitar se refiere tan sólo a aquella que diga relación con la prestación del servicio, el ejercicio de funciones delegadas de control u otro tipo de funciones administrativas, sin que alcancen a aspectos de la organización empresarial o de las demás actividades de la entidad.

Esta obligación se extiende a los adjudicatarios de contratos del sector público "en los términos previstos en el respectivo contrato". Como puede verse, queda a la interpretación si la Administración es libre de imponer o no obligaciones de transparencia en los contratos, lo que fue ya criticado por el Consejo de Estado en su Dictamen 707/2012, de 19 de julio, al Anteproyecto de Ley. El art. 4.2 LTA añade que "los pliegos de cláusulas administrativas particulares o documento contractual equivalente especificarán dicha obligación", lo que parece indicar la voluntad del legislador autonómico de imponer estas obligaciones de publicidad.

La LTA ha extendido también esta obligación a los beneficiarios de las subvenciones pero, una vez más, "en los términos previstos en las bases reguladoras de las subvenciones y en la resolución de concesión" y parece también en estos casos imponer la previsión de estas estipulaciones por cuando establece que "las bases reguladoras de la concesión de subvenciones, las resoluciones de concesión o los convenios que instrumenten la concesión de subvenciones recogerán de forma expresa esta obligación".

En todo caso, el art. 4.5 determina que "los medios personales y materiales necesarios" para garantizar el cumplimiento de esta obligación de suministrar información, "serán valorados por las administraciones, organismos o entidades previstas en el art. 3.1 y, a tal fin, deberán establecerse las previsiones necesarias en los contratos del sector público y en las bases reguladoras de las subvenciones para posibilitar su observancia".

También como novedad de la LTA respecto a la LTBG se prevé que las administraciones públicas andaluzas puedan acordar, previo apercibimiento y audiencia del interesado, la imposición de multas coercitivas una vez transcurrido el plazo con- 
ferido en el requerimiento. La multa, de 100 a 1.000 euros, será reiterada por períodos de quince días hasta el cumplimiento, sin que pueda exceder en todo caso, del $5 \%$ del importe del contrato, subvención o instrumento administrativo que habilite para el ejercicio de las funciones públicas o la prestación de los servicios, o, si no figura una cuantía concreta, de 3.000 euros. Para la determinación del importe dentro de la banda de 100 a 1.000 euros, se atenderá a la gravedad del incumplimiento y al principio de proporcionalidad, entre otros. De esta forma, queda cubierta la reserva legal impuesta por el art. 99.1 LRJPAC para la imposición por la Administración de multas coercitivas (que, recuérdese, no tienen carácter sancionador y por ello son compatibles con la imposición de sanciones, previstas en el Título VI LTA, como veremos).

Por lo demás, la disposición transitoria segunda LTA dispone que las obligaciones establecidas en este precepto "nacen de la Ley y, en consecuencia, no será obstáculo para su exigibilidad, a partir de la entrada en vigor de esta ley, el mero hecho de que el contrato, subvención o cualesquiera otras formas de relación, estando vigentes, tengan su origen en una fecha anterior"

Junto al denominado "ámbito subjetivo de aplicación” (arts. 2 LTBG y 3 LTA) y a las entidades privadas no incluidas en el mismo pero sobre las que pesa una "obligación de suministrar información” (arts. 4 LTBG y 4 LTA), se encuentran los denominados "otros sujetos obligados" (art. 3 LTBG y 5 LTA). Se trata de una inclusión que trae causa de la incorporación en la tramitación de la LTBG en el Congreso de los Diputados de un nuevo artículo, el 3, que extendió las obligaciones de publicidad activa también a los partidos políticos, las organizaciones sindicales y empresariales, de una parte y en todo caso, y a las entidades privadas (la LTA ha desgranado que se trata de "las iglesias, confesiones, asociaciones, instituciones, entidades representativas de intereses colectivos y otras entidades") que perciban durante el periodo de un año ayudas o subvenciones públicas en una cuantía superior a 100.000 euros o cuando al menos el 40 por ciento del total de sus ingresos anuales tengan carácter de ayuda o subvención pública, siempre que alcancen, como mínimo, la cantidad de 5.000 euros. Obsérvese que al emplearse el término "entidades" parece excluirse a las personas físicas (lo que quizás no esté justificado en el caso de empresarios individuales, pues puede determinar que ante una misma actividad, dependa la publicidad de haber o no adoptado forma societaria).

Esta incorporación de última hora trató de dar respuesta a un clamor ciudadano y mediático y también a una propuesta coincidente en la comparecencia de los expertos. El debate, de hecho, no se centró en si todos los sujetos que, como los citados, reciben fondos públicos en una proporción sustancial de sus presupuestos debían dar cuenta de su empleo, sino más bien en si las medidas de transparencia debían ser acogidas en la propia LTBG o en su normativa reguladora, de una parte, y, en caso de 
acogerse la primera solución, si debía de serles de aplicación plena o tan sólo en lo relativo a la publicidad activa. Triunfó la opción de incluirlas en la LTBG tan sólo en lo relativo a la publicidad activa (y, dentro de ella, sólo en lo relativo a información que por su naturaleza fuera susceptible de afectarles, excluyendo la característica sólo de las Administraciones, como los planes y programas, la información de relevancia jurídica, o la relación de bienes inmuebles). Ahora bien, que no se ha precisado que la publicidad se refiera a la transparencia tan sólo del destino de los fondos que reciben, sino a todas las materias enumeradas en los arts. 6 a 8, que incluyen organización, contratos, convenios, presupuestos, cuentas anuales...), lo que tiene un alcance muy extenso $^{12}$. Habrá que esperar, probablemente, a ver cómo las autoridades de control y la jurisprudencia interpretan esta obligación.

La LTA da un paso más, al establecer que, con independencia de los límites anteriores, cuando estas entidades accedan a la financiación de sus actividades y funcionamiento ordinario a través de subvenciones y ayudas financiadas con cargo al presupuesto de la Junta de Andalucía podrán ser sometidas, además, a exigencias de publicidad específicas aplicando criterios de transparencia análogos a los previstos en materia de publicidad activa para las entidades sujetas, en los términos que establezcan las disposiciones de desarrollo de la LTA y las correspondientes convocatorias, respetando en todo caso la naturaleza privada de estas entidades y las finalidades que las mismas tienen reconocida.

También como adición del art. 5.2 LTA, las normas reguladoras de los conciertos y otras formas de participación de entidades privadas en los sistemas públicos de educación y deportes, sanidad y servicios sociales han de establecer aquellas obligaciones de publicidad activa, de entre las que establece la presente ley, que deban

${ }^{12} \mathrm{El}$ art. 8.2 dice: "2. Los sujetos mencionados en el artículo 3 deberán publicar la información a la que se refieren las letras a) y b) del apartado primero de este artículo cuando se trate de contratos o convenios celebrados con una Administración Pública. Asimismo, habrán de publicar la información prevista en la letra c) en relación a las subvenciones que reciban cuando el órgano concedente sea una Administración Pública." El precepto parece limitar las obligaciones de estos sujetos en materia de información económica, presupuestaria y estadística a esas materias. Sin embargo, ese apartado es fruto de la aprobación de dos enmiendas con esa literalidad, una de GiU (la núm. 400) y otra del Partido Popular (la núm. 521). La primera se justificaba como "adaptación técnica de acuerdo con la naturaleza jurídica de los sujetos obligados" y la segunda del siguiente modo: "Como consecuencia de la inclusión en el ámbito de aplicación de sujetos que no tienen naturaleza pública, se especifica el alcance de las disposiciones del artículo 7, que se aplicarán en su totalidad con las especificaciones que se fijan en la enmienda respecto de la información a la que se refieren las letras a), b) y c)." Como puede comprobarse, la redacción del precepto y su procedencia generan una notable inseguirdad acerca del alcance de las obligaciones de publicidad activa de estas entidades. 
cumplir estas entidades para colaborar en la prestación de estos servicios sufragados con fondos públicos. Estas obligaciones se incluirán en los pliegos o documentos contractuales equivalentes que correspondan. De nuevo hay que hacer aquí extensiva la reflexión sobre la malla de publicidades que acabamos de formular con respecto a las subvenciones.

Finalmente, en el ámbito local, el art. 5.3 LTA dispone que además de la obligación de suministro de información regulada en el art. 4, las empresas prestadoras de servicios públicos locales en régimen de gestión indirecta deberán cumplir ellas mismas con las obligaciones de publicidad activa, de entre las previstas en la LTA, que se determinen reglamentariamente para hacer efectivo el principio de transparencia financiera y en la gestión de los servicios locales de interés general previsto en el art. 27.8 LAULA, que tendrán el carácter de comunes y mínimas y podrán ser complementadas con otras por las entidades locales. Al respecto, añade que "las ordenanzas reguladoras de la prestación del servicio público y los pliegos o documentos equivalentes habrán de recoger dichas obligaciones de publicidad activa".

Como puede comprobarse, la LTA ha ido más allá que la estatal en el sometimiento de los sujetos privados al principio de transparencia, si bien queda deferido el alcance al desarrollo reglamentario autonómico y local y a lo dispuesto en cada convocatoria. Sólo el futuro nos dará pues su justa medida, futuro en que las entidades locales tienen un importante poder de decisión.

\section{PRINCIPIOS BÁSICOS, DERECHOS Y OBLIGACIONES}

La LTA ha establecido un catálogo de principios básicos ${ }^{13}$, derechos ${ }^{14}$ y obligaciones ${ }^{15}$ que, en realidad, son derivaciones del propio contenido de la legislación básica estatal y de la propia LTA y que, acaso, pueden tener valor pedagógico. Por lo demás, en su formulación, no presentan especialidades en el ámbito local.

${ }^{13}$ Son los de transparencia, libre acceso a la información pública, de responsabilidad, no discriminación tecnológica, veracidad, utilidad, gratuidad, facilidad y comprensión, accesibilidad, interoperabilidad y reutilización.

${ }^{14}$ Así, el derecho a la publicidad activa, de acceso a la información pública, a obtener una resolución motivada y al uso de la información obtenida.

${ }^{15}$ Ejercer su derecho con respeto a los principios de buena fe e interdicción del abuso de derecho, realizar el acceso a la información de forma que no se vea afectada la eficacia del funcionamiento de los servicios públicos, concretándose lo más precisamente posible la petición, respetar las obligaciones establecidas en la normativa básica para la reutilización de la información obtenida y 


\section{LÍMITES A LA TRANSPARENCIA Y EL ACGESO A LA IN- FORMACIÓN}

La LTA, como no podía ser de otro modo, al tener carácter básico, ha remitido la regulación de los límites a la LTBG ya que es materia con carácter básico ${ }^{16}$. Por la misma razón, las entidades locales no podrían ampliar ni reducir dichos límites (con el añadido de que, en el caso de las normas locales, se trataría de limitar un derecho constitucional por vía reglamentaria).

La LTA tan sólo añade a la regulación estatal algo que se deriva de ella pero que no se encuentra expresado en la LTBG, que "las limitaciones al derecho de acceso solo serán de aplicación durante el período de tiempo determinado por las leyes o en tanto se mantenga la razón que las justifique". Además, y en el caso del límite de la protección de datos personales, que es que ha de jugar principalmente en el ámbito local (y no otros como la defensa nacional, las relaciones exteriores, etc. ${ }^{17}$, dispone que "de conformidad con lo previsto en la legislación básica de acceso a la información pública, para la resolución de las solicitudes de acceso a la información pública que contengan datos personales de la propia persona solicitante o de terceras personas, se estará a lo dispuesto en la Ley 19/2013, de 9 de diciembre, y en la Ley Orgánica 15/1999, de 13 de diciembre". Se trata de un precepto que no contribuye a aclarar la cuestión sino más bien a la confusión. En efecto, el proyecto de LTBG disponía que las solicitudes de información que contengan datos personales de terceros se regían por la LTBG y sólo en el caso de que los únicos datos contenidos sean los

cumplir las condiciones y requisitos materiales para el acceso que se hayan señalado en la correspondiente resolución cuando el acceso se realice de forma presencial en un archivo o dependencia pública.

${ }^{16}$ Sobre este tema, véase GUICHOT, E., "Límites a la transparencia y el acceso a la información”, en E. GUICHOT (coord.), Transparencia..., op. cit., pp. 97-142; FERNÁNDEZ RAMOS, S., en RAMOS FERNÁNDEZ, S. y PÉREZ MONGUIÓ, J. M., Transparencia..., op. cit., pp. 162-211; o SENDÍN GARCÍA, M. A., en RODRÍGUEZ-ARANA, J. y SENDÍN GARCÍA, M. A., Transparencia..., op. cit., pp. 160-174.

${ }^{17}$ Sobre las relaciones entre publicidad y privacidad antes de la aprobación de la LTBG, véanse GUICHOT, E., Publicidad y privacidad de la información administrativa, Civitas, Madrid, 2009 y PIÑAR MAÑAS, J. L., "Transparencia y protección de datos: las claves de un equilibrio necesario", en RUIZ OJEDA, A. L., (coord.), El gobierno local. Estudios en homenaje al profesor Luis Morell Ocaña, Iustel, Madrid, 2010, pp. 1023-1044. Tras la aprobación de la LTBG, además de las obras citadas con carácter general respecto de los límites, específicamente sobre la protección de datos, MARTÍNEZ MARTÍNEZ, R., "De la opacidad a la casa de cristal. El conflicto entre publicidad y transparencia", en VALERO TORRIJOS, J. y FERNÁNDEZ SALMERÓN, M., Régimen jurídico de la transparencia del sector público..., op. cit., pp. 241-280. 
del propio solicitante de información sería de aplicación la normativa sobre protección de datos. Este principio se eliminó en la tramitación parlamentaria por innecesario, puesto que las relaciones de generalidad-especialidad en la aplicación de las leyes derivan de los principios generales del ordenamiento. Sin embargo, como ya advirtieron algunos expertos, se trataba de una aclaración de gran utilidad para el aplicador, dado que la cuestión puede prestarse a interpretaciones diferentes que pueden suponer una cerrazón de la transparencia por mera invocación de la normativa de protección de datos dando origen a un reenvío incierto entre bloques normativos. La "precisión" de la LTA puede contribuir a esta confusión o, como mínimo, no aclara nada.

\section{PUBLICIDAD ACTIVA}

La publicidad activa, es, sin duda, la gran tendencia revolucionaria en materia de transparencia y acceso a la información, fundamentalmente de la mano de Internet.

La LTBG regula este tema en sus arts. 5 a 11, en el capítulo II del Título I, que regulan, junto a principios generales, materias concretas sometidas a publicidad obligatoria en internet $^{18}$. La LTA lo desarrolla notablemente en sus arts. 9 a 23, estableciendo en el art. 17 que se fomentará la ampliación de la lista, ya muy amplia, que contempla la LTA, y que el Consejo de Gobierno de la Junta de Andalucía y las entidades locales podrán ampliar reglamentariamente dicho listado.

Los arts. 5 LTBG y 9 LTA regulan una serie de aspectos comunes. El principio general es la publicación de la información "cuyo conocimiento sea relevante para garantizar la transparencia de su actividad relacionada con el funcionamiento y control de la actuación pública", con aplicación de los límites antes estudiados. Además, se prevé que se dé publicidad a la información que se solicite con mayor frecuencia (lo que la LTBG prevé para la AGE en su art. 10.2 y el art. 17.1 la LTA extiende a las Administraciones andaluzas) y que en el caso de la Administración de la Junta, se extiende a toda la información que se haya facilitado en el ejercicio del derecho de acceso en la medida en que las posibilidades técnicas y jurídicas lo permitan (art. 17.2 LTA), principio éste que las entidades locales son libres también de asumir. Asimis-

${ }^{18}$ Sobre el particular, BARRERO, C., GUICHOT, E y HORGUÉ, C., "Publicidad activa", en GUICHOT, E. (coord.), Transparencia..., op. cit., pp. 143-198, FERNÁNDEZ RAMOS, S., en FERNÁNDEZ RAMOS, S. y PÉREZ MONGUIÓ, J. M., Transparencia ..., op. cit., pp. 101-147, o SENDÍN GARCÍA, M. A., en RODRÍGUEZ-ARANA, J. y SENDÍN GARCÍA, M. A., Transparencia..., op. cit., pp. 129-138. 
mo se alude al fomento de la inclusión de cualquier información que se considere de interés para la ciudadanía (art. 17.1 LTA).

La LTBG prevé en los arts. 6 a 8 la publicación de toda una serie de información sumamente relevante, clasificada en "institucional, organizativa y de planificación", la información "de relevancia jurídica", y la información "económica, presupuestaria y estadística". Este listado ha sido desarrollado y parcialmente reclasificado en los arts. 10 y ss. LTA. Son, en síntesis, los siguientes:

a) Información institucional y organizativa: se trata de información sobre las funciones que desarrollan los obligados por la LTA, la normativa que les sea de aplicación y, en particular, los estatutos y normas de organización y funcionamiento de los entes instrumentales, su estructura organizativa, a cuyos efectos se publicará un organigrama actualizado que identifique a las personas responsables de los diferentes órganos ${ }^{19}$ (lo que plantea problemas de identificación en el ámbito $l o c a l^{20}$ ), y su perfil y trayectoria profesional (currículos) y la identificación de las personas responsables de las unidades administrativas, sede física, horarios de atención al publico, teléfono y dirección de correo electrónico, delegaciones de competencia vigentes, relación de órganos colegiados adscritos y normas por las que se rigen, relaciones de puestos de trabajo, catálogo de puestos o documento equivalente, referidos a todo tipo de personal, con indicación de sus retribuciones anuales (la Ordenanza Tipo de la FEMP se refiere expresamente al "número de puestos de trabajo reservados a personal eventual), las resoluciones de autorización o reconocimiento de compatibilidad que afecten a empleados públicos, los acuerdos o pactos reguladores de las condiciones de trabajo y convenios colectivos vigentes, la oferta pública de empleo u otro instrumento similar de gestión de la provisión de necesidades de personal, los procesos de selección del personal, la identificación de las personas que forman parte de los órganos de repre-

${ }^{19}$ La Ordenanza Tipo de la FEMP se refiere a los distintos órganos decisorios, consultivos, de participación o de gestión, especificando su sede, composición y competencias.

${ }^{20}$ Como es sabido, el art. 130 LBRL diferencia para los municipios de gran población entre órganos de gobierno - el Alcalde y los miembros de la Junta de Gobierno Local- y órganos directivos - los coordinadores generales de cada área o concejalía, los directores generales u órganos similares que culminen la organización administrativa dentro de cada una de las grandes áreas o concejalías, el titular del órgano de apoyo a la Junta de Gobierno Local y el concejal-secretario de la misma; el titular de la asesoría jurídica, el secretario general del pleno, el interventor general municipal y en su caso el titular del órgano de gestión tributaria, así como los titulares de los máximos órganos de dirección de los organismos autónomos y de las entidades públicas empresariales locales; para el resto de municipios no hay un patrón preestablecido, si bien puede pensarse en que se publicite la organización hasta nivel de puestos de responsabilidad como jefaturas de servicio o de áreas, y teniendo en cuenta que también se establece la publicidad obligatoria de la relación de puestos de trabajo. 
sentación del personal y el número de personas que gozan de dispensa total de asistencia al trabajo, y las agendas institucionales de los gobiernos. Se dispone expresamente que las entidades locales publicarán, además, la información cuya publicidad viene establecida en la LAULA así como las actas de las sesiones plenarias ${ }^{21}$.

b) Información sobre altos cargos y personas que ejerzan la máxima responsabilidad de las entidades incluidas en el ámbito de aplicación de la Ley, que incluye las retribuciones "de cualquier naturaleza" (léase, incluidas las dietas) percibidas anualmente, las indemnizaciones por cese y las declaraciones anuales de bienes y actividades de los representantes locales, en los términos previstos en la LBRL, con omisión de los datos relativos a la localización concreta de los bienes inmuebles y con garantía de la privacidad y la seguridad de las personas ${ }^{22}$. Plantea el problema de la indefinición del concepto de alto cargo en la escala local. Pudiera pensarse que los órganos de gobierno y directivos de los municipios de gran población pueden equipararse a "altos cargos" y, en el resto, aquellos existentes de entre los allí señalados ${ }^{23}$.

c) Información sobre planificación y evaluación. Los planes y programas anuales y plurianuales que se aprueben en los que se fijen objetivos concretos (en el ámbito local no hay una categorización uniforme, entrarían aquí, por ejemplo, los planes de legislatura, estratégicos, sectoriales, etc.), con evaluación de su grado de cumplimiento y resultados junto con los indicadores de medida y valoración. Se publicarán tan pronto sean aprobados y, en todo caso, en el plazo máximo de 20 días, y permanecerán publicados mientras estén vigentes, sin perjuicios de los plazos más breves que puedan establecer las entidades locales en ejercicio de su autonomía.

d) Información de relevancia jurídica. Incluye cualquier instrumento (directrices, circulares, acuerdos...) que supongan una interpretación del Derecho o tengan efectos jurídicos (de especial relevancia en material urbanística o ambiental), los proyectos de reglamentos "en el momento en que, en su caso, se sometan al trámite de audiencia o información pública", sin que la publicación suponga, necesariamente, la apertura de estos trámites. En el ámbito de las entidades locales, una vez efectuada la aprobación inicial de la ordenanza o reglamento local por el Pleno de la Corporación, deberá publicarse el texto de la versión inicial, sin perjuicio de otras exigencias que pudieran establecerse por las entidades locales en ejercicio de su autonomía. Además,

${ }^{21}$ La Ordenanza Tipo de la FEMP establece como directriz que esta información se mantenga publicada mientras dure su vigencia.

${ }^{22}$ La Ordenanza Tipo de la FEMP añade la publicación de las resoluciones que autoricen el ejercicio de actividad privada con motivo del cese de los mismos.

${ }^{23}$ La Ordenanza Tipo de la FEMP establece como directriz que esta información se mantenga publicada mientras dure su vigencia. 
se publicarán las memorias e informes que conformen los expedientes de elaboración de los textos normativos con ocasión de la publicidad de los mismos, los documentos que conforme a la legislación sectorial deban ser sometidos a un periodo de información pública durante su tramitación y la relación actualizada de las normas que estén en curso, indicando su objeto y estado de tramitación ${ }^{24}$.

e) Información sobre procedimientos, cartas de servicio y participación ciudadana. Aquí se incluyen el catálogo actualizado de los procedimientos administrativos de su competencia, con indicación de su objeto, trámites y plazos, así como en su caso los formularios que tengan asociados y con indicación de los que admitan total o parcialmente la tramitación electrónica; las cartas de servicios, los informes sobre el grado de cumplimiento y calidad de los servicios públicos, así como la información disponible que permita su valoración; y una relación de los procedimientos en los que sean posible a participación de la ciudadanía mientras se encuentren en trámite ${ }^{25}$.

f) Información sobre contratos, convenios y subvenciones. Comprende una multitud de datos que afectan a todos (también los menores) los contratos (objeto, duración, importe de licitación y de adjudicación, procedimiento utilizado para su celebración, instrumentos a través de los que, en su caso, se haya publicitado, número de licitadores participantes e identidad del adjudicatario, modificaciones y prórrogas, procedimientos que han quedado desiertos, resolución de contratos y declaraciones de nulidad, revisiones de precio y cesión de contratos, desistimientos y renuncias y subcontrataciones con mención de los adjudicatarios, estadísticas sobre el volumen de los contratos adjudicados a través de cada tipo de procedimiento; la Ordenanza Tipo de la FEMP añade el perfil del contratante), los convenios y encomiendas de gestión y todas las subvenciones (no solo las de publicación obligada según la Ley General de Subvenciones $)^{26}$.

g) Información económica, financiera y presupuestaria. Abarca los presupuestos, con descripción de las principales partidas, con información "actualizada y comprensible"

${ }^{24}$ La Ordenanza Tipo de la FEMP refiere la publicación al texto completo de las ordenanzas, reglamentos y otras disposiciones, los proyectos de estas normas y los informes que conformen el expediente de elaboración, y reproduce la norma estatal según la cual cuando sea preceptiva la solicitud de dictámenes de órganos consultivos, la publicación se produzca una vez solicitados y añade, también siguiendo el modelo estatal, la relación de bienes inmuebles que sean de su propiedad o sobre los que ostenten algún derecho real.

${ }^{25}$ La Ordenanza Tipo de la FEMP prevé su publicidad mientras que la información mantenga su vigencia.

${ }^{26}$ La Ordenanza Tipo de la FEMP prevé que esta información se mantenga publicada mientras persistan las obligaciones derivadas de los mismos y, al menos, dos años después de que éstas cesen. 
sobre su estado de ejecución, el cumplimiento de las obligaciones de estabilidad presupuestaria y sostenibilidad financiera y la información sobre las actuaciones de control, en este ultimo caso "en los términos que se establezcan reglamentariamente"27, las cuentas anuales que deban rendirse y los informes de auditoria de cuentas y fiscalización de órganos de control externos ${ }^{28}$, o el gasto publico realizado en campañas de publicidad institucional (podría haberse dicho expresamente que desglosado por cada medio de comunicación, para aumentar el control) ${ }^{29}$.

h) Específicamente para las entidades locales, el art. 21 LTA dispone que "cuando las entidades locales celebren sesiones plenarias, facilitarán, salvo que concurran causas justificadas de imposibilidad técnica o económica, su acceso a través de internet, bien transmitiendo la sesión, bien dando acceso al archiva audiovisual grabado una vez celebrada la misma". No se trata, ya por tanto de una facultad, como aparece en el 88.2 ROF, sino de una obligación. Además, se dispone que "en todo caso, las personas asistentes podrán realizar la grabación de las sesiones por sus propios medios, respetando el funcionamiento ordinario de la Institución" (así, con sus propios teléfonos móviles o cámaras portátiles), solventando así una cuestión que en la jurisprudencia quedaba, como dijimos, a lo que dispusiera el Reglamento Orgánico o la decisión ad hoc del Alcalde o Presidente ${ }^{30}$.

i) El art. 22 LTA ha generalizado una medida de transparencia adoptada meses antes respecto del Consejo de Gobierno de la Junta de Andalucía y dispone que tanto éste como los órganos colegiados de gobierno de los ayuntamientos, diputaciones y mancomunidades de municipios, sin perjuicio del secreto o reserva de sus deliberaciones, harán públicos con carácter previo a la celebración de sus reuniones el orden del día previsto y, una vez celebradas, los acuerdos que se hayan aprobado, así como la información contenida en el expediente que se haya sometido a su consideración, en los términos que se establezcan reglamentariamente." Como apuntamos en el primer epígrafe, hasta la LTA las convocatorias y ordenes del día debían transmitirse a los medios de comunicación social de la localidad y publicarse en el tablón

27 La Ordenanza Tipo de la FEMP habla de actualización al menos trimestral y añade información sobre las modificaciones presupuestarias realizadas y la liquidación del presupuesto.

${ }^{28} \mathrm{Ni}$ la ley estatal ni la andaluza ni la Ordenanza Tipo de la FEMP han incluido los informes de órganos de control internos.

${ }^{29}$ La Ordenanza Tipo de la FEMP añade la publicación de la masa salarial del personal laboral del sector público local, en los términos regulados en el art. 103 bis LBRL. Prevé que toda esta información se publique durante cinco años a partir del momento en que fue generada.

30 Sobre el particular, véase FERNÁNDEZ RAMOS, S., La información y participación..., op. cit., pp. 62-64. 
de anuncios de las Corporaciones, conforme al art. 229.1 ROF, y notificarse a las asociaciones vecinales registradas, cuando así lo soliciten expresamente y en el orden del día figuren cuestiones relacionadas con el objeto social de la entidad, art. 234.a) ROF. Ahora se añade la publicidad a través de internet, no sólo de los órdenes del día sino también de los acuerdos y de los informes en que se basan, eso sí, en los términos que se dispongan reglamentariamente.

A todo esto ha de unirse los preceptos que comentamos en el primer epígrafe tanto de la LBRL como de la LAULA (en particular, su art. 54) que prevén obligaciones de publicidad en toda una extensa serie de materias, algunas incluidas en el catálogo de la LTA y otras no ${ }^{31}$. La publicación ha de hacerse en las correspondientes "sedes electrónicas o páginas web”. Ciertamente, la obligación de llevar una página web que cumpla con los requisitos impuestos a la publicidad activa puede ser una carga importante para algunos de los sujetos obligados que tienen poca capacidad de recursos humanos y económicos. La LTBG prevé que las entidades sin ánimo de lucro que persigan exclusivamente fines de interés social o cultural y cuyo presupuesto sea inferior a 50.000 euros, puedan cumplir con sus obligaciones de publicidad activa utilizando los medios electrónicos puestos a su disposición por la Administración Pública de la que provenga la mayor parte de las ayudas o subvenciones públicas percibidas. Para la Administración estatal se prevé la creación de un Portal de Transparencia (art. 10 LTBG) y para la autonómica la publicidad a través del Portal de la Junta de Andalucía (art. 18). El apartado segundo del art. 18 LTA prevé que la Administración de la Junta de Andalucía pueda adoptar medidas de colaboración con el resto de administraciones públicas para el cumplimiento de las obligaciones de transparencia, que pueden instrumentarse mediante convenio administrativo. Y por su parte el art. 20, denominado "auxilio institucional" prevé que sin perjuicio de esa formula de colaboración, aquellos municipios de menor población o con insuficiente capacidad económica y de gestión puedan cumplir con las obligaciones de publicidad activa acudiendo a la asistencia técnica de la provincia al municipio prevista en el art. 12 LAULA o conforme a lo previsto en el art. 54

${ }^{31} \mathrm{Al}$ respecto, puede anotarse que respecto a la información sobre ordenación territorial, ordenación y disciplina urbanísticas y proyectos para su ejecución, prevista en el citado artículo de la LAULA, la Ordenanza Tipo de la FEMP se refiere al texto completo y la planimetría de los instrumentos de planeamiento urbanístico y sus modificaciones, así como los convenios urbanísticos. Y que respecto a la información sobre medio ambiente, también presente en el listado del art. 54 LAULA, la Ordenanza Tipo de la FEMP precisa como información que debería publicarse los textos normativos aplicables en materia de medioambiente; las políticas, programas y planes de la Entidad Local relativos al medioambiente, así como los informes de seguimiento de los mismos, los datos relativos a la calidad de los recursos naturales y del medio ambiente urbano, incluyendo la calidad del aire y del agua, información sobre niveles polínicos y contaminación acústica, los estudios de impacto ambiental, paisajísticos y evaluaciones del riesgo relativos a elementos medioambientales. 
LAULA con respecto a la publicación en sede electrónica de la respectiva Diputación Provincial. Es decir, formulas de colaboración que llaman a que la falta de recursos propios no pueda aducirse como causa de imposibilidad de cumplimiento de la transparencia ante los ciudadanos.

Se prevé la publicación "de forma periódica y actualizada". La LTBG no establece plazos concretos. En mi opinión, la LTBG parte de un principio de permanente actualización. Algunas muestras pueden rastrearse en el propio texto de la norma. Así, en esta lógica se mueve el principio de carácter básico enunciado en el art. 21.1, conforme al cual las Administraciones Públicas deben establecer sistemas para integrar la gestión de solicitudes de información de los ciudadanos en el funcionamiento de su organización interna. Lo mismo podría predicarse de la publicidad activa. En todo caso, el art. 9.7 LTA dispone que se hará trimestralmente, salvo que la normativa específica establezca otros plazos atendiendo a las peculiaridades propias de la información de que se trate y sin perjuicio de los plazos que puedan establecer las entidades locales en ejercicio de su autonomía. La publicidad debe responder a los principios de acceso gratuito, fácil, universal e interoperable, calidad, claridad y estructuración, "identificabilidad" y "localizabilidad", comprensibilidad y inteligibilidad, y "reutilizabilidad", "preferiblemente", principio éste que conecta directamente la LTBG con los proyectos de open data y plantea la ardua cuestión de cuál sea la conexión de la LTBG y la Ley 37/2007, de 16 de noviembre, sobre reutilización de la información del sector público. Como se dijo, el art. 19 LTA, denominado "reutilización de la información", establece que se podrá reutilizar la información a la que se refieren los artículos anteriores dentro de los límites establecidos por la Ley 37/2007, de 16 de noviembre, sobre reutilización de la información del sector público, y demás normativa vigente en la materia. A estos efectos, la información que tenga la consideración de publicidad activa se ofrecerá, siempre que sea técnicamente posible, en formatos electrónicos que permitan su redistribución, reutilización y aprovechamiento. La información deberá utilizar estándares abiertos en los términos previstos en la Ley 11/2007, de 22 de junio, de acceso electrónico de los ciudadanos a los Servicios Públicos.

\section{DERECHO DE ACGESO A LA INFORMACIÓN PÚBLICA O PUBLICIDAD PASIVA}

La otra cara de la publicidad activa es la publicidad pasiva o "derecho de acceso a la información pública", mecanismo no limitado ya a categorías de información, como la publicidad activa, sino general $^{32}$.

32 Véase BARRERO, C., "El derecho de acceso a la información: publicidad pasiva", en GUICHOT, E. (coord.), Transparencia..., op. cit., pp. 199-246; FERNÁNDEZ RAMOS, S., en 
El amplio entendimiento que el legislador estatal ha hecho de lo básico en este punto hace que al legislador autonómico le haya quedado muy poco margen de maniobra, que la LTA ha apurado del siguiente modo:

La LTBG establece en su art. 18 causas de inadmisión, mediante resolución motivada, que suponen un complemento en negativo a esta amplia definición inicial del objeto del derecho de acceso como referido a información (y no a documentos, como en muchas leyes de nuestro entorno). El art. 30 LTA ha precisado las más relevantes:

a) En primer lugar, las que se refieran a información que esté en curso de elaboración o de publicación general, que se justifica porque se trata de información o bien en plena redacción o bien que destinada a una pronta publicación activa. La LTA impone que en estos casos la denegación deba especificar el órgano que elabora la información y el tiempo previsto para su conclusión y puesta en disposición ${ }^{33}$.

b) En segundo lugar, se excluyen las solicitudes que se refieran a información tenga carácter auxiliar o de apoyo "como la contenida en notas, borradores, opiniones, resúmenes, comunicaciones e informes internos o entre órganos o entidades administrativas" (art. 18.1.b LTBG). La mención a los informes internos, por su ambigüedad, puede dar lugar a abusos. La LTA ha precisado que los informes preceptivos no pueden ser considerados como información de carácter auxiliar o de apoyo para justificar la inadmisión de las solicitudes referidas a los mismos.

a) En tercer lugar, se ha tenido que establecer alguna restricción ante la posibilidad de solicitudes segundo que conviertan a los sujetos obligados en auténticos "consultores" al servicio de cualquier solicitante, y al respecto establece que se exceptúan del derecho de acceso la información para cuya divulgación "sea necesaria una acción previa de reelaboración" (art. 18.1.c LTBG), concepto éste cuya interpretación más o menos amplia va a ser uno de los elementos nucleares de la aplicación de la Ley. La LTA ha precisado que no se estima reelaboración que justifique la inadmisión la información que pueda obtenerse mediante un tratamiento informatizado de uso corriente.

La LTBG regula el procedimiento de ejercicio del derecho de acceso con carác-

FERNÁNDEZ RAMOS, S. y PÉREZ MONGUIÓ, J. M., Transparencia..., op. cit., pp. 149-162 y 213-253, o SENDÍN GARCíA, M. A., en RODRÍGUEZ-ARANA, J. y SENDÍN GARCÍA, M. A., Transparencia..., op. cit., pp. 139-160 y 175-188.

${ }^{33}$ Esto último previsto también en la Ordenanza Tipo de la FEMP. 
ter básico para todas las Administraciones, de forma que la LTA comienza su regulación en paralelo afirmando que el procedimiento se rige por lo establecido en la legislación básica a la que en todo caso precisa y complementa.

Sus aportaciones son las siguientes:

La LTBG establece libertad de medios para la solicitud, siempre que permita tener constancia de la identidad del solicitante, la información que se solicita, una dirección de contacto, preferentemente electrónica, a efectos de comunicaciones y, en su caso, la modalidad que se prefiera para acceder a la información solicitada. No es precisa la motivación ni la acreditación de interés alguno. El art. 29 LTA se refiere al fomento de la tramitación electrónica. Llama a las personas o entidades incluidas en su ámbito de aplicación (incluidas por tanto las entidades locales) a promover la presentación de las solicitudes por vía telemática, sin perjuicio de la vigencia del principio de no discriminación tecnológica, y dispone que en todo caso tendrán disponibles en sus respectivas sedes electrónicas, portales o páginas web, al menos, los modelos normalizados de solicitud (en el ámbito de la Administración de la Junta de Andalucía, la presentación electrónica de las solicitudes de acceso se prevé a través del Portal de la Junta de Andalucía, solución ésta que puede ser voluntariamente acogida por el resto de entidades respecto de sus respectivos portales).

Deberá dirigirse al titular del órgano administrativo o entidad que posea la información (cuando se trate de información en posesión de personas físicas o jurídicas que presten servicios públicos o ejerzan potestades administrativas, la solicitud ha de dirigirse a la Administración, organismo o entidad a las que se encuentren vinculadas). En cuanto al órgano competente para resolver, el art. 28 LTA establece que lo será el órgano o la entidad que lo sea en la materia a la que se refiera la información solicitada. En las entidades locales, parece remitir a la distribución de competencias entre Alcalde/Presidente y Pleno derivada de la LBRL y la de LAULA. Y que cuando la persona interesada conozca la ubicación concreta de un documento o información en un archivo determinado, puede dirigirse al órgano responsable del mismo en los términos previstos en la legislación en materia de archivos. El art. 31 LTA recoge un deber de auxilio y colaboración, conforme al cual las entidades sujetas a la Ley deben establecer en sus respectivas plataformas de información y guías de orientación, para facilitar a las personas que deseen ejercer el derecho de acceso, la orientación necesaria para localizar la información que solicitan y los órganos que la posean. Además, el personal al servicio de estas entidades está obligado a ayudar e informar a las personas que lo requieran de la forma y el lugar en que pueden presentar sus solicitudes. En todo ello ha de atenderse especialmente a las necesidades de las personas con discapacidad o con otras circunstancias personales que les dificulten el acceso a la información disponible en las administraciones públicas o a los medios electrónicos. 
El plazo de resolución acogido en el art. 20.1 LTBG se mueve dentro de parámetros comparados razonables: de un máximo de un mes desde la recepción por el órgano competente para resolver, ampliable por otro mes en el caso de que el volumen o la complejidad de la información que se solicita así lo hagan necesario, previa notificación al solicitante. No obstante, en uso de sus competencias, los sujetos obligados pueden reducir (que no ampliar, al ser una garantía básica) normativamente dicho plazo. La LTA, tras precisar que las solicitudes deben resolverse y notificarse en el menor plazo posible, ha dispuesto que en todo caso en el ámbito de la Administración de la Junta de Andalucía y sus entidades instrumentales, el plazo máximo es de 20 días hábiles, prorrogables por igual período en los mismos casos y condiciones previstos en la LTBG.

La LTA no se pronuncia sobre el sentido del silencio, que ha de entenderse negativo por aplicación del precepto básico de la $\mathrm{LTBG}^{34}$. Las entidades locales no podrían tampoco cambiar esta regla por esta misma razón.

El art. 22.1 LTBG dispone que, salvo petición en contrario, la regla es la transmisión electrónica de la información, siempre, claro, que se haya consignado una dirección electrónica en la solicitud. Si hay petición expresa de otra forma de acceso, la información se entrega al solicitante en la forma y formato por él elegidos, salvo

\footnotetext{
${ }^{34}$ En el panorama autonómico, el art. 46.3 del proyecto de ley de transparencia y acceso a la información pública de Canarias establece expresamente el silencio negativo. En el mismo sentido se sitúa el artículo 103.3 del proyecto de ley de la Administración pública vasca. Las leyes extremeña y andaluza no dicen nada al respecto y la Ley riojana se limita a señalar en su art. 13.1 que: "El derecho de acceso a la información pública se ejercerá conforme al procedimiento establecido en la legislación básica del Estado. Puede interpretarse que el silencio es negativo de conformidad con la Ley básica estatal (aunque se siembra la duda por la falta de una declaración expresa, ante la regla supletoria de la LRJPAC de silencio positivo). En esta línea de no pronunciarse sobre el sentido del silencio se sitúa el proyecto de ley del Principado de Asturias de transparencia. Contribuye aún más a la inseguridad jurídica la Ley Foral 11/20"12, de 21 de junio, de la Transparencia y del Gobierno Abierto en su art. 30.2, que establece: Si en el plazo máximo previsto para resolver y notificar no se hubiese recibido resolución expresa, se entenderá estimada la solicitud salvo con relación a la información cuya denegación, total o parcial, viniera expresamente impuesta en una norma con rango de ley." ¿Son los límites del art. 14 y 15 una de esas excepciones? Pero si lo son, ¿cómo va a entenderse que concurren sin una resolución expresa tras examen del fondo del asunto? ¿Es el silencio negativo de la ley básica estatal un caso de imposición expresa del silencio negativo a los efectos de la ley navarra? Esta cláusula resulta, pues, tanto en su regla general como en su inextricable excepción, sumamente desafortunada. Lo peor es que esta fórmula comienza a ser copiada en algún proyecto de ley autonómica (véase el artículo 31.2 del proyecto de ley de transparencia pública y participación ciudadana de Aragón, o el 35.1 de la proposición de ley de transparencia, acceso a la información pública y buen gobierno).
} 
que pueda ocasionar la pérdida o deterioro del soporte original, no exista equipo técnico disponible para realizar la copia en ese formato, pueda afectar al derecho de propiedad intelectual o exista una forma o formado más sencilla o económica para el erario público, como dispone el art. 34.1 LTA, que también precisa que en todo caso, si la información se transmite en formato electrónico, debe suministrarse en estándar abierto o, en su defecto, debe ser legible con aplicaciones informáticas que no requieran licencia comercial de uso.

Cuando no pueda darse el acceso en el momento de la notificación de la resolución deberá otorgarse, en cualquier caso, en un plazo no superior a diez días. Ahora bien, si ha existido oposición de tercero, el acceso sólo tendrá lugar cuando, habiéndose concedido dicho acceso, haya transcurrido el plazo para interponer recurso contencioso administrativo sin que se haya formalizado o haya sido resuelto conformando el derecho a recibir información (en realidad debería entenderse hasta que se trate de una resolución firme, porque si la resolución judicial es susceptible de recurso ulterior entregar la información desproveería de sentido al mismo al dejarlo sin objeto $)^{35}$.

Cuando la información ya ha sido publicada, basta como indicar al solicitante cómo puede acceder a ella.

El acceso es gratuito (cuando, como precisa el art. 34.3, se accede al original en el sitio donde se encuentre o la información se remite por medios electrónicos). La LTBG establece que la expedición de copias o la transposición de la información a un formato diferente al original pueden dar lugar a la exigencia de exacciones, de conformidad con la normativa autonómica o local que resulte aplicable. A estos efectos, el art. 34.2 LTA impone a las entidades y órganos obligados la publicación y puesta a disposición de los solicitantes del listado de tasas y precios públicos que sean de aplicación, así como los supuestos en los que no proceda pago alguno, si bien dispone que "en ningún caso, la imposibilidad o incapacidad de hacer frente a las tasas o precios públicos establecidos podrán ser causa para negar el acceso pleno a una información pública solicitada al amparo de la presente ley, en los términos que reglamentariamente se establezcan", dando así acogida a una regla de exención del pago a las personas que no alcancen un volumen de ingresos que debe ser precisado reglamentariamente.

${ }^{35}$ La Ordenanza Tipo de la FEMP prevé que el acceso pueda condicionarse al transcurso de un plazo determinado cuando la causa de denegación esté vinculada a un interés que afecte exclusivamente a la entidad local competente. 
Las resoluciones dictadas en materia de acceso a la información pública son recurribles directamente ante la Jurisdicción Contencioso-administrativa (cualquiera que sea la naturaleza, pública o privada, del sujeto ante el que se presentó la solicitud), sin perjuicio de la posibilidad de interposición de una reclamación potestativa ante una autoridad independiente, el Consejo de Transparencia y Protección de Datos de Andalucía, en nuestro caso, que analizaremos más adelante. Se trata de una reclamación sustitutiva de los recursos administrativos, allí donde cupieran (pues no todos los sujetos obligados son Administración pública ni se rigen por la LRJPAC).

La competencia para la resolución de los recursos contencioso-administrativo viene determinada, de conformidad con las reglas establecidas por la propia LJCA, por el órgano autor de la resolución impugnada. Conviene advertir que se producirán variaciones en función de que se haya interpuesto directamente el recurso contenciosoadministrativo o se haya hecho uso de la reclamación previa. En efecto, conforme al art. 8.1 LJCA, la competencia para conocer de los recursos frente a actos de las entidades locales o de las entidades y corporaciones dependientes o vinculadas a las mismas (salvo los instrumentos de planeamiento urbanístico) corresponde a los juzgados de lo contencioso-administrativo, mientras que los actos de las Administraciones de las Comunidades Autónomas cuyo conocimiento no esté atribuido a los Juzgados de lo Contencioso-Administrativo (art. 10.1.a) y cualesquiera otras actuaciones administrativas no atribuidas expresamente a la competencia de otros órganos del orden jurisdiccional contencioso-administrativo (art. 10.1.m) son de la competencia de los Tribunales Superiores de Justicia. De este modo, en el caso de las solicitudes de acceso a la información dirigidas a las entidades locales, la competencia para conocer de los recursos corresponderá o bien a los juzgados de lo contencioso-administrativo de la provincia a la que pertenezca la entidad local en cuestión, o, si se optó por formular reclamación previa ante el Consejo de Transparencia y Protección de Datos de Andalucía, al Tribunal Superior de Justicia de Andalucía. Probablemente lo más coherente sería atribuir en todo caso la competencia a éste último, pero para ello sería necesaria una reforma por ley estatal de la LJCA.

\section{FOMENTO DE LA TRANSPARENGIA, ORGANIZACIÓN Y CONTROL. EL CONSEJO DE TRANSPARENCIA Y PRO- TEGCIÓN DE DATOS DE ANDALUCÍA}

\section{Fomento}

Cumplir con las obligaciones de publicidad activa y pasiva supone un auténtico reto para las Administraciones. De nada sirve una ley bien diseñada si faltan los recursos humanos y materiales para llevarla a la realidad. Se requiere una nueva, moderna y eficaz gestión de la información. Los arts. 21.1 LTBG y 35.1 LTA obligan a 
todas las Administraciones Públicas incluidas en su ámbito de aplicación a establecer sistemas para integrar la gestión de solicitudes de información de los ciudadanos en el funcionamiento de su organización interna. El art. 35.2 dispone, además, que deben establecer medidas para facilitar la transversalidad de la transparencia en la actividad general de la organización.

La LTA avanza en la formulación de otra serie de principios respecto a las bases estatales. Se refiere así a:

a) Conservación de la información de conformidad con la normativa vigente (tema que conecta con la aplicación efectiva de la normativa archivística) y, en todo caso, en estándares abiertos que garanticen su longevidad y manteniendo la capacidad de transformarlos automáticamente a formatos de fácil reproducción y acceso siempre que sea técnicamente posible.

b) Fomento de iniciativas de interoperabilidad entre Administraciones públicas por parte de la Administración de la Junta de Andalucía, propiciando iniciativas conjuntas de intercambio de información entre las entidades incluidas en el ámbito de aplicación de la LTA.

c) Formación de los empleados públicos, en especial los que deban atender las funciones de información, en relación con la publicidad activa y pasiva.

d) Divulgación para facilitar el conocimiento por la ciudadanía de la información que resulta accesible y de los cauces para poder acceder a ella, especialmente en referencia a la accesibilidad que en cada caso esté disponible por medios electrónicos (piénsese en campañas de publicidad institucional, carteles en las dependencias administrativas, edición de guías ciudadanas con lenguaje comprensible para el ciudadano, etc.).

\section{Organización}

El enorme reto que supone dar cumplimiento en plazo a las obligaciones de publicidad activa y pasiva que imponen la LTBG y la LTA requiere una coordinación en cada Administración de las funciones informativas.

Para la Administración General del Estado, el art. 21.2 ha previsto la creación de las llamadas "Unidades especializadas de Información". El resto de entidades son libres para establecer su organización, siempre que identifiquen claramente el órgano competente para conocer de las solicitudes de acceso.

En el caso de la Administración de la Junta de Andalucía y de sus entidades y organismos adscritos, conforme al art. 40 LTA, hay una estructura en red conformada 
por la Comisión General de Viceconsejeros y Viceconsejeras, con funciones de coordinación general, y unidades y comisiones de transparencia, en cada Consejería, y la Inspección General de Servicios de la funta de Andalucía, a la que se le encarga velar por el cumplimiento de las obligaciones de publicidad activa y pasiva. Junto a estas disposiciones organizativas, se prevé que cada consejería establezca un plan operativo.

Como puede notarse, tanto el Estado como las Comunidades Autónomas han previsto todo un dispositivo organizativo al servicio del cumplimiento de las obligaciones de transparencia. Queda a cada entidad local, al ser materia organizativa que entra de pleno en su ámbito de autonomía, decidir su propio modelo. Como es sabido, el art. 230 ROF prevé la existencia de Oficinas de Información, que podrían ser las llamadas a realizar las funciones de gestión bajo la dirección del Secretario.

\section{Control}

LA LTBG impone la existencia de una autoridad independiente que conozca de las reclamaciones frente a las resoluciones en materia de acceso a la información. Debe recalcarse que se tratan de resoluciones que sustituyen a los recursos administrativos y están dotadas por ello de plena fuerza ejecutiva y ejecutoria, es decir, son vinculantes y de obligado cumplimiento, a expensas de la posibilidad de impugnación ante los tribunales contencioso-administrativos, como vimos, y del efecto suspensivo de este eventual recurso sobre su eficacia ${ }^{36}$.

El Título III de la LTBG regula una autoridad administrativa independiente de nueva creación, el Consejo de Transparencia y Buen Gobierno, encargada de promover la transparencia de la actividad pública, velar por el cumplimiento de las obligaciones de publicidad, salvaguardar el ejercicio del derecho de acceso a la información pública y garantizar la observancia de las disposiciones de Buen Gobierno. Ahora bien, ejerce sus funciones sólo en el ámbito estatal, por lo que no tiene sentido extendernos aquí en su composición y funciones.

El Título III no tiene carácter básico, lo que resulta absolutamente coherente con el diseño de reparto de competencias constitucional. Ahora bien, esa misma disposición adicional apela al art. 149.1.1 ${ }^{\text {a }}$ de la Constitución, título que tiene su juego en la

${ }^{35}$ Sobre el Consejo de Transparencia y Buen Gobierno, véase GUICHOT, E., "El Consejo de Transparencia y Buen Gobierno”, en GUICHOT, E. (coord.), Transparencia..., op. cit., pp. 331-351; FERNÁNDEZ RAMOS, S., en FERNÁNDEZ RAMOS, S. y PÉREZ MONGUIÓ, J. M., Transparencia..., op. cit., pp. 255-284; GARCÍA COSTA, F. M., "El Consejo de Transparencia y Buen Gobierno", en VALERO TORRIJOS, J. y FERNÁNDEZ SALMERÓN, M., Régimen jurídico de la transparencia del sector público, op. cit., pp. 483-504. 
LTBG precisamente en materia de garantías uniformes en la tutela del derecho de acceso a la información. La disposición adicional cuarta dispone, desde su versión inicial, que la resolución de la reclamación corresponde, en los supuestos de resoluciones dictadas por las Administraciones de las Comunidades Autónomas y su sector público, y por las Entidades Locales comprendidas en su ámbito territorial, "al órgano independiente que determinen las Comunidades Autónomas". Optativamente, permite a las Comunidades Autónomas y a las Ciudades Autónomas atribuir la resolución de las reclamaciones al CTBG, siempre que celebren el correspondiente convenio con la AGE, en el que se estipulen las condiciones en que la Comunidad sufragará los gastos derivados de esta asunción de competencias. Obsérvese que en el caso de las Entidades Locales, la LTBG también opta, aparentemente, por una solución similar a la contenida en la LOPD, la de atribuir la competencia a un órgano independiente autonómico.

La LTA ha creado una nueva institución, el Consejo de Transparencia y Protección de Datos de Andalucía (CTPDA), como autoridad independiente de control en materia de protección de datos y de transparencia en la Comunidad Autónoma, que ejerce sus competencias tanto respecto de la Administración autonómica como de la local.

Como puede notarse, la LTA ha optado por unificar en una sola Autoridad independiente las competencias en materia de transparencia y protección de datos, lo que parece una solución particularmente afortunada en materia autonómica y local, en el que el principal límite a la primera es la segunda y es necesario soluciones que conforme a lo dispuesto en la LTBG y en la LTA armonicen ambos derechos y resuelvan los conflictos a que pueda darse lugar de forma homogénea, en pro de la seguridad jurídica ${ }^{37}$.

La Ley le da las máximas notas de garantía: se trata de una entidad pública con personalidad jurídica propia, con plena capacidad y autonomía orgánica y funcional para el ejercicio de sus cometidos, que debe ejercer con objetividad, profesionalidad, sometimiento al ordenamiento jurídico y plena independencia de las administraciones públicas en el ejercicio de los mismos. Su relación con la Administración de la Junta de Andalucía se lleva a cabo a través de la Consejería de Presidencia, lo que debe entenderse en un sentido puramente burocrático sin condicionante alguno a su

${ }^{37}$ Sobre las ventajas e inconvenientes de la unificación de competencias en una misma autoridad en los ámbitos estatal y autonómico, y favorable a ello en el autonómico, me pronuncié ya en Transparencia y Acceso a la Información en España: análisis y propuestas legislativas, Fundación Alternativas, Madrid, 2011, pp. X, y posteriormente en El Proyecto de Ley de Transparencia..., op. cit., p. X. 
independencia, en particular para la integración de su presupuesto en los Presupuestos Generales de la Junta de Andalucía.

El CTPDA (cuya regulación detallada - estructura, competencias, organización y funcionamiento- tendrá lugar en sus estatutos que apruebe el Consejo de Gobierno de la Junta de Andalucía) se estructura en dos órganos:

a) La Dirección: su titular será nombrado por el Consejo de Gobierno por un período de 5 años no renovables (si bien continuará en el ejercicio de sus funciones hasta la toma de posesión del nuevo titular). La prohibición de renovación del mandato es una garantía de que las decisiones no sean tomadas influidas por la expectativa de una futura renovación. Su designación corresponde al Parlamento de Andalucía, por mayoría absoluta (al igual que ocurre en el ámbito estatal con el CTBG, se exige pues una mayoría cualificada de este género, y no superior de $3 / 5$ o 2/3, como podría haber sido aún más conveniente), y deberá recaer en una persona de reconocido prestigio y competencia profesional, que ejercerá sus funciones con plena independencia y objetividad y no estará sujeta a instrucción alguna en el desempeño de aquéllas. Tan sólo deberá oír a la Comisión Consultiva en aquellas propuestas que ésta le realice en el ejercicio de sus funciones. Las causas de cese son tasadas: muerte o incapacitación judicial, renuncia o separación acordada por el Consejo de Gobierno (nótese, no por el Parlamento por mayoría absoluta, también siguiendo el modelo estatal del CTBG), previa instrucción de expediente, en el que necesariamente será oída la Comisión Consultiva (garantía inexistente en el modelo estatal), por incumplimiento grave de sus obligaciones, incapacidad sobrevenida para el ejercicio de su función, incompatibilidad sobrevenida o condena por delito doloso. Concentra todas las funciones ejecutivas: representa al Consejo, resuelve las reclamaciones contra las decisiones en materia de acceso a la información, adopta criterios de interpretación uniforme de las obligaciones contenidas en la LTA; presenta ante el Parlamento de Andalucía un informe anual de actuación; resuelve las consultas que en materia de transparencia o protección de datos le planteen las administraciones y entidades sujetas a la LTA (no así los ciudadanos); responde a las consultas que, con carácter facultativo, le planteen los órganos encargados de tramitar y resolver las solicitudes de acceso a la información, así como las consultas que respecto a la transparencia en el funcionamiento de los gobiernos prevista en el art. 22 LTA le planteen los órganos competentes; ejerce el control de la publicidad activa por iniciativa propia o como consecuencia de denuncia, formulando requerimientos para la subsanación de incumplimientos, sin perjuicio del control interno que establezca cada entidad o Administración de acuerdo con sus propias normas organizativas; insta la incoación de expedientes disciplinarios o sancionadores de acuerdo con las previsiones del régimen sancionador de la propia LTA, que analizaremos en el siguiente epígrafe y desempeña las funciones previstas en la legislación sobre protección de datos para su ejercicio por las agencias autonómicas. 
b) La Comisión consultiva: es el órgano de participación y consulta en materia de transparencia y protección de datos, que asesora a la persona que ejerza la Dirección. La componen dicha persona, que la preside, y catorce miembros en representación de: la Administración de la Junta de Andalucía, el Parlamento de Andalucía, reuniendo la condición de diputado o diputada, las administraciones locales andaluzas, las universidades públicas andaluzas, las entidades representativas de las personas consumidoras y usuarias, las entidades representativas de los intereses económicos y sociales, personas expertas en la materia, la Oficina del Defensor del Pueblo Andaluz y de la Cámara de Cuentas de Andalucía. Nótese que salvo en estos dos últimos casos, no se ha precisado cuántos representantes corresponden a cada uno de ellos (entre los cuáles están las administraciones locales andaluzas), lo que se deja, junto a la precisión de las funciones, funcionamiento y composición a lo que se determine en los estatutos del Consejo. Los miembros son nombrados por la persona titular de la Consejería de Presidencia y son cesados por las mismas causas tasadas que la persona que ejerza la Dirección del Consejo o a petición de la entidad que los hubiera propuesto.

\section{RÉGIMEN SANGIONADOR}

La LTBG es muy parca en lo que se refiere al régimen sancionador por el incumplimiento de sus previsiones. Tan sólo, y ante las críticas que suscitó durante la tramitación pre-parlamentaria y parlamentaria a ausencia de previsión de sanciones, castiga como infracción grave a los efectos de la normativa de régimen disciplinario los incumplimientos reiterados de las obligaciones de publicidad activa (art. 9.3) o de la obligación de resolver en plazo las solicitudes de acceso (art. 20.6) ${ }^{38}$.

Esta parquedad contrasta con la completa regulación contenida en el Título VI LTA (arts. 50 a 58).

Se declara responsables de las infracciones, aun a título de simple inobservancia, a las personas físicas o jurídicas, cualquiera que sea su naturaleza, que realicen acciones o que incurran en las omisiones tipificadas en la LTA con dolo, culpa o negligencia.

\footnotetext{
38 Sobre estas previsiones, véase BAUZÁ MARTORELL, F., "La potestad sancionadora frente al incumplimiento de la normativa sobre acceso, transparencia y reutilización de la información", en VALERO TORRIJOS, J. y FERNÁNDEZ SALMERÓN, M., Régimen jurídico de la transparencia del sector público, op. cit., pp. 459-481.
} 
Acoge una clasificación de las infracciones en muy graves, graves y leves.

a) En el caso de las autoridades, directivos y personal al servicio de las entidades enumeradas en su art. 3 se califican como:

- Muy graves el incumplimiento de las obligaciones de publicidad activa cuando se haya atendido el requerimiento expreso del CTPDA; la denegación arbitraria (concepto éste indeterminado) del derecho de acceso a la información pública; el incumplimiento de las resoluciones dictadas en materia de acceso por el CTPDA en las reclamaciones que se le hayan representado

- Graves: el incumplimiento reiterado de las obligaciones de publicidad activa, el incumplimiento reiterado de la obligación de resolver en plazo las solicitudes de acceso a la información, la falta de colaboración en la tramitación de las reclamaciones que se presenten ante el CTPDA, y el suministro de información incumpliendo las exigencias derivadas del principio de veracidad.

- Leves: el incumplimiento de las obligaciones de publicidad activa, el incumplimiento injustificado de la obligación de resolver en plazo la solicitud de acceso a la información pública (en ambos casos, cuando son puntuales, y no reiterados)

En estos casos, cuando sean imputables al personal al servicio de estas entidades se le aplicarán las sanciones que correspondan según su régimen disciplinario. Si son imputables a autoridades y directivos, podrán aplicarse las siguientes sanciones: para las leves, amonestación; para las graves, declaración del incumplimiento y publicación en el boletín oficial correspondiente y cese en el cargo; y para las muy graves todas las previstas para las graves e imposibilidad de ser nombrados para ocupar cargos similares (concepto indeterminado) por un período de hasta tres años.

b) En el caso de las personas fisicas y jurídicas obligadas al suministro de información conforme al art. 4 LTA se califican como:

- Muy graves: el incumplimiento de la obligación de suministro de información que haya sido reclamada como consecuencia de un requerimiento del CTPDA o para dar cumplimiento a una resolución del mismo en materia de acceso y la reincidencia en la comisión de faltas graves, entendiéndose por tal la comisión en el término de un año de más de una infracción de la misma naturaleza cuando así haya sido declarado por resolución firme.

- Graves: la falta de contestación al requerimiento de información, el suministro de información incumplimiento las exigencias derivadas del principio de vera- 
cidad y la reincidencia en la comisión de faltas leves, entendiéndose por tal la comisión en el término de un año de más de una infracción de la misma naturaleza cuando así haya sido declarado por resolución firme.

- Leves: el retraso injustificado en el suministro de información y el suministro parcial o en condiciones distintas de las reclamadas.

c) En el caso de las entidades de naturaleza privada referidas en el art. 5 LTA se califican como:

- Muy grave: el incumplimiento de las obligaciones de publicidad activa que les sean de aplicación cuando se haya desatendido el requerimiento expreso del CTPDA.

- Grave: el incumplimiento reiterado de las obligaciones de publicidad activa que les sean de aplicación o la publicación de la información incumpliendo las exigencias derivadas del principio de veracidad.

- Leve: el incumplimiento de las obligaciones de publicidad activa que les sean de aplicación cuando no constituya infracción grave o muy grave.

En los casos de las letras b) y c), al tratarse de entidades privadas, se prevén sanciones de amonestaciones y multas. En concreto, para las leves amonestación o multa de entre 200 y 5.000 euros; para las graves, multa de entre 5.001 y 30.000 euros; para las muy graves, multa de entre 30.001 y 400.000 euros. Además, en el caso de las graves y muy graves, podrán conllevar como sanción accesoria el reintegro total o parcial de la subvención concedida o, en su caso, la resolución del contrato, concierto o vínculo establecido. Para la imposición y graduación de estas sanciones accesorias, se atenderá a la gravedad de los hechos y su repercusión, de acuerdo con el principio de proporcionalidad.

Como puede verse, se trata de un régimen sancionador muy severo.

El procedimiento para la imposición de las sanciones será el general previsto en materia disciplinaria o sancionadora, en función de la naturaleza del responsable. En todo caso, se iniciará de oficio, por acuerdo del órgano competente, bien por propia iniciativa o como consecuencia de orden superior, petición razonada de otros órganos o denuncia de la ciudadanía. El CTPDA, cuando constate incumplimientos susceptibles de ser calificados como alguna de las infracciones antes referidas, instará la incoación del procedimiento. En este último caso, el órgano competente está obligado a incoar el procedimiento y a comunicar al Consejo el resultado del mismo, lo que vuelve a poner de manifiesto el papel poderoso y central del CTPDA en la aplicación de la LTA. 
La competencia para la imposición de las sanciones disciplinarias corresponde al órgano que determine la normativa aplicable en la Administración o entidad a la que pertenezca el sujeto infractor. En las entidades locales, esto plantea el problema que supone su ejercicio cuando la infracción sea imputable precisamente al Alcalde o Presidente, en casos en que el CTPDA haya instado la incoación del procedimiento sancionador (disciplinario).

Para las cometidas por sujetos privados obligados al suministro de información, la competencia corresponde al órgano que determine la normativa aplicable en la Administración o entidad a la que se encuentre vinculada la persona infractora. En el caso de las cometidas por otros sujetos privados con obligaciones de publicidad activa, la potestad sancionadora será ejercida por la Consejería de la Junta de Andalucía competente en materia de la Presidencia o por la entidad local titular del servicio público.

\section{LA RELACIÓN DE LAS LEYES DE TRANSPARENGIA CON OTRAS NORMAS QUE REGULAN EL AGGESO A LA IN- FORMACIÓN. EN PARTICULAR, EL ACGESO POR LOS CONGEJALES A LA INFORMACIÓN MUNICIPAL}

Un tema final de importancia es el que se refiere a su ámbito negativo de aplicación, que viene regulado en idénticos términos en la disposición adicional primera LTBG y en la disposición adicional cuarta LTA, tituladas "regulaciones especiales del derecho de acceso a la información"39.

\section{La relación con otros bloques normativos: acceso a documen- tos de procedimientos en curso, normativas especiales y legis- lación sobre archivos}

- En lo que hace a la relación con las normas de procedimiento el primer apartado establece que "la normativa reguladora del correspondiente procedimiento administrativo será la aplicable al acceso por parte de quienes tengan la condición de interesados en un procedimiento administrativo en curso a los documentos que se integren en el mismo." Debe recordarse al efecto que el art. 35.a) LRJPAC establece entre los derechos de los ciudadanos el de conocer, en cualquier momento, el estado de la tramitación de los procedimientos en los que tengan la condición de interesa-

${ }^{39} \mathrm{El}$ razonamiento lo desarrollé in extenso en GUICHOT, E., "Transparencia: aspectos generales", en GUICHOT, E. (coord.), Transparencia..., op. cit., pp. 50-62. 
dos, y obtener copias de documentos contenidos en ellos". La distinción básica en cuanto a su alcance, que en la regulación de la LRJPAC anterior a la LTBG estribaba en el binomio interesado-procedimiento en curso/cualquier ciudadano-procedimiento terminado, ha quedado diluida en la medida en que la LTBG, a diferencia de la regulación precedente en el art. 37 LRJPAC, no limita el derecho de acceso a que la información se halle en expedientes terminados y archivados, por lo que cabe cuestionarse cuál es ahora la virtualidad de la distinción. Parece que, en todo caso, nunca podría ser de peor condición el acceso por el interesado que el acceso por terceros y que los derechos de contradicción y defensa deberían conllevar una inaplicación o una aplicación más reducida de los valores protegidos por algunos de los límites contemplados en el art. 14 LTBG como los relativos a la prevención, investigación y sanción de los ilícitos penales, administrativos o disciplinarios, las funciones administrativas de vigilancia, inspección y control, la garantía de la confidencialidad o el secreto requerido en procesos de toma de decisión.

- El segundo apartado establece que "se regirán por su normativa específica, y por esta Ley con carácter supletorio, aquellas materias que tengan previsto un régimen jurídico específico de acceso a la información.” La LTBG no desvela cuáles sean estas normativas específicas, a diferencia de lo que hace el propio art. 37 LRJPAC, en su apartado quinto (materias excluidas) y sexto (materias que se rigen por su normativa específica). Se trata de normas que regulan de forma adaptada a la realidad sobre la que se proyectan las condiciones de acceso a la información. Obsérvese, por lo demás, que no se exige que la normativa específica esté contenida en una norma con rango de ley, y aparentemente admite que por vía reglamentaria se establezcan regímenes diferentes, lo que tiene un enorme potencial disgregador del régimen común establecido por la LTBG que quizás no haya sido previsto por el legislador. En seguida entraremos en la aplicación de esta regla al acceso de los concejales a la información municipal.

- El tercer apartado, dispone que "en este sentido, esta Ley será de aplicación, en lo no previsto en sus respectivas normas reguladoras, al acceso a la información ambiental y a la destinada a la reutilización". El alcance de esta previsión de supletorio no es evidente, sobre todo una vez que se incorporó ya al apartado segundo la referencia general a la supletorio de la LTBG. Se plantea, en todo caso, a qué extremos se extiende la supletorio. Por ejemplo, ¿ha de interpretarse que por esta vía puede producirse una ampliación de los sujetos obligados respecto de los previstos en la normativa específica? ¿Cabe ampliar los límites previstos en la normativa específica que no estén en ellas contemplados pero sí en la LTBG? ¿Debe interpretarse que en caso de omisión de previsión sobre el sentido del silencio éste debe entenderse como negativo por aplicación de la LTBG? ¿Hay que colegir que el régimen de reclamación frente a denegaciones parciales o totales o desestimaciones presuntas es de aplicación supletoria y la competencia de las autoridades independientes se extiende ahora tam- 
bién a todas las materias? En mi opinión, desde luego, ha de descartarse que la supletorio se aplique al contenido sustantivo de estas normas, ampliándose el abanico de los sujetos o los límites; son aspectos regulados en cada caso del modo que se ha estimado conveniente para la materia en cuestión. Más cuestionable es si podría extenderse el régimen del silencio negativo a los casos de información ambiental, donde la Ley que lo regula no dice nada y donde además el legislador estatal actúa sólo como legislador básico. En el caso de la normativa sobre reutilización, el silencio se contempla como negativo. Probablemente el sentido de esta norma, en la mente del legislador, estuvo en extender las garantías de tutela por una autoridad independiente pero tampoco es tan evidente, en la medida en que la propia Ley de acceso a la información ambiental regula en su art. 20 las vías de recurso (administrativo y contencioso) y por tanto no es pacífico que se trate de un aspecto "no regulado", lo que no ocurre con la ley de reutilización, en cuyo caso -y habida cuenta la intima relación entre las materias y, aún más, la dificultad que tendrá el deslindar cuándo es de aplicación una u otra ley-me parece más fácilmente defendible que sí es de aplicación supletoria esta garantía. Sólo la práctica de las autoridades independientes y, en su caso, la jurisprudencia, contribuirá a despejar estas incógnitas.

- La LTBG, por lo demás, no determina las relaciones con la normativa sobre archivos. Por conectadas que estén las materias reguladas en la LTBG y en la normativa sobre archivos, hay que partir de la idea de que la LTBG no es ni ha querido ser una Ley básica de archivos (que probablemente convenga un día, antes que tarde, afrontar, eliminando la disfunción histórica de hacer colgar los archivos administrativos de la materia "cultura" y no de las "bases del régimen jurídico de las Administraciones Públicas"). El Proyecto incluía en el ámbito de aplicación de la LTBG sólo el acceso a la información obrante en archivos de gestión u oficina, dejando al margen la información obrante en el resto de archivos (en el sistema estatal, los llamados generales, intermedios e históricos). Esta disposición planteaba evidente e irresolubles problemas para su aplicación, y fue eliminada durante la tramitación en el Congreso de los Diputados, de tal forma que la LTBG rige ahora con carácter básico el acceso a la información cualquiera que sea el archivo en que obre el documento que la contiene, si lo hace en alguno. Ahora bien, al no haberse derogado expresamente el art. 57 de la Ley 16/1985, de 25 de junio, del Patrimonio Histórico Español (LPHE), que regula el acceso a los archivos que no tienen la calificación de gestión u oficina, se ha introducido una notable inseguridad jurídica, que se acrecienta con la mención a dicho artículo en el art. 15.3.a) LTBG al establecer entre los criterios para valorar cuándo debe prevalecer la publicidad y cuándo la reserva en el caso de información que contenga datos personales, el del menor perjuicio a los afectados "derivado del transcurso de los plazos establecidos en el art. 57 de la Ley 16/1985, de 25 de junio, del Patrimonio Histórico Español”. El art. 57 LPHE, además, es de desgraciada redacción, pues no se acompasa en los límites a los de la LTBG y regula los plazos en que deja de jugar el límite a la intimidad de forma deficiente y probablemente inconstitucional, ya que conduce a la posibilidad de dar acceso 
documentos de más de cincuenta años de antigüedad pese a que afecten a la intimidad de terceros, contra la configuración del derecho a la intimidad como personalísimo. En todo caso, su falta de derogación expresa unida a su esta vez sí expresa (e incoherente) mención en el art. 15 LTBG va a llevar a una auténtica esquizofrenia a los aplicadores del Derecho. Por el contrario, la LTA sí ha regulado de forma convincente estas relaciones en su disposición final tercera, que modifica la Ley 7/2011, de 3 de noviembre, de Documentos, Archivos y Patrimonio Documental de Andalucía. De este modo:

a) Modifica la regulación de la Comisión Andaluza de Valoración de Documentos, a la que corresponde la valoración de los documentos de titularidad pública y la aplicación del régimen de acceso material al patrimonio documental de Andalucía custodiado en los archivos del Sistema, y se incluye entre sus competencias el establecimiento de los criterios sobre el acceso material a los documentos de titularidad pública y a los documentos del Patrimonio Documental de Andalucía custodiados en los archivos del Sistema, de conformidad con la LTA

b) Establece que el acceso a los documentos de titularidad pública y a su información se ajustará a lo dispuesto en la Constitución, en la Ley de Transparencia, Acceso a la Información Pública y Buen Gobierno, en la Ley de Transparencia Pública de Andalucía, en la presente ley y demás normas que resulten de aplicación

c) Regula el acceso estableciendo que los límites y causas de inadmisión serán los de la LTBG y la LTA; que el acceso material a los documentos podrá ser denegado cuando el estado de conservación de los mismos así lo requiera, pudiendo ser sustituido por una reproducción veraz; que se denegará la consulta directa de los documentos originales a las personas que hayan sido condenadas por sentencia firme por la comisión de delitos contra la seguridad y conservación del Patrimonio Documental (quedando exceptuada de esta limitación la consulta de los documentos pertenecientes a procedimientos en los que sean parte interesada); y que la Comisión Andaluza de Valoración de Documentos podrá establecer criterios homogéneos sobre la aplicación de la normativa sobre la materialización del acceso a los archivos, en los términos previstos en la legislación sobre transparencia, considerando el estado de conservación de los documentos.

d) Finalmente, añade al catálogo de infracciones la consistente en impedir el derecho de acceso de la ciudadanía a los archivos en las condiciones antes mencionadas.

\section{En particular, el acceso por los concejales a la información municipal}

Acceder a la información municipal es un requisito necesario para que los concejales puedan ejercer su labor y conecta de este modo, como ha reiterado la juris- 
prudencia, con el derecho a la participación en la vida pública a través de representantes del art. $23 \mathrm{CE}^{40}$.

$\mathrm{El}$ art. 77 LBRL dispone que todos los miembros de las Corporaciones locales tienen derecho a obtener del Alcalde o Presidente o de la Comisión de Gobierno (léase, Junta de Gobierno Local) cuantos antecedentes, datos o informaciones obren en poder de los servicios de la Corporación y resulten precisos para el desarrollo de su función, y que la solicitud de ejercicio de este derecho ha de ser resuelta motivadamente en los cinco días naturales siguientes a aquél en que se hubiese presentado. Este artículo está desarrollado en los arts. 14 al 16 ROF.

- El art. 14 establece el silencio positivo.

- El art. 15 dispone que los servicios administrativos locales están obligados a facilitar la información, sin necesidad de que el miembro de la Corporación acredite estar autorizado, en los siguientes casos:

a) Cuando se trate del acceso de los miembros de la Corporación que ostenten delegaciones o responsabilidades de gestión, a la información propia de las mismas.

b) Cuando se trate del acceso de cualquier miembro de la Corporación, a la información y documentación correspondiente a los asuntos que hayan de ser tratados por los órganos colegiados de que formen parte, así como a las resoluciones o acuerdos adoptados por cualquier órgano municipal.

c) Cuando se trate del acceso de los miembros de la Corporación a la información o documentación de la entidad local que sean de libre acceso para los ciudadanos.

- El art. 16 dispone que la consulta y examen concreto de los expedientes, libros y documentación en general se regirá por las siguientes normas:

a) La consulta general de cualquier expediente o antecedentes documentales podrá realizarse, bien en el archivo general o en la dependencia donde se encuentre, bien mediante la entrega de los mismos o de copia al miembro de la

${ }^{40}$ Sobre el tema véase la completa y rigurosa exposición en FERNÁNDEZ RAMOS, S., Los concejales y el acceso a la información. El derecho de los concejales de acceso a la documentación local, $2^{\mathrm{a}}$ ed., Comares, Granada, 2003. 
Corporación interesado para que pueda examinarlos en el despacho o salas reservadas a los miembros de la Corporación. En este supuesto, y a efectos del oportuno control administrativo, el interesado deberá firmar un acuse de recibo y tendrá la obligación de devolver el expediente o documentación en un término máximo de cuarenta y ocho horas, o antes, en función de las necesidades del trámite del expediente en cuestión. El libramiento de copias se limitará a los casos citados de acceso libre de los Concejales a la información y a los casos en que ello sea expresamente autorizado por el Presidente de la Comisión de Gobierno (léase, Junta de Gobierno Local).

b) En ningún caso los expedientes, libros o documentación podrán salir de la Casa Consistorial o Palacio Provincial, o de las correspondientes dependencias y oficinas locales.

c) La consulta de los libros de actas y los libros de resoluciones del Presidente deberá efectuarse en el archivo o en la Secretaría General.

d) El examen de expedientes sometidos a sesión podrá hacerse únicamente en el lugar en que se encuentren de manifiesto a partir de la convocatoria.

Los miembros de la Corporación tienen el deber de guardar reserva en relación con las informaciones que se les faciliten para hacer posible el desarrollo de su función, singularmente de las que han de servir de antecedente para decisiones que aún se encuentren pendientes de adopción, así como para evitar la reproducción de la documentación que pueda serles facilitada, en original o copia, para su estudio.

Esta normativa ha de ser ahora cohonestada con la normativa sobre transparencia que hemos analizado. Pueden sacarse algunas conclusiones:

a) En ningún caso, los concejales, como representantes de los ciudadanos democráticamente elegidos, pueden entenderse situados en una peor condición para acceder a la información municipal que los propios ciudadanos. Esta regla debe proyectarse sobre cualquier interpretación de las reglas establecidas en la LBRL o en el ROF.

b) Los concejales no han de motivar la solicitud de información, al igual que no tienen por qué hacerlo los ciudadanos, como hemos visto, según la LTBG y la LTA. Esta era ya la interpretación mayoritaria de la jurisprudencia (por todas Sentencia del Tribunal Supremo de 26 de junio de 1998).

c) Sólo pueden rechazarse peticiones abusivas, lo que debe interpretarse en un sentido muy limitado (como apunta por todas la Sentencia del Tribunal Su- 
premo de 28 de mayo de 1997). Recuérdese que el art. 18.1.e) LTBG sólo permite la inadmisión, mediante resolución motivada, de las solicitudes que sean manifiestamente repetitivas o tengan un carácter abusivo no justificado con la finalidad de transparencia que se persigue.

d) A la luz de la nueva normativa sobre transparencia, resulta muy discutible la previsión del ROF, que limita el derecho a obtener copias de la información a una serie de casos de libre de los Concejales a la información, que antes citamos, y a los casos en que ello sea expresamente autorizado por el Presidente de la Comisión de Gobierno (léase, Junta de Gobierno Local). Parece inconsecuente que los ciudadanos tengan derecho a solicitar el acceso mediante envío de copias, de forma gratuita si son en formato electrónico, y se le niegue a sus representantes locales, por lo que esta disposición podría entenderse superada, siempre, claro, que no se ejerza el derecho de forma abusiva pidiendo copias de series documentales extensísimas no justificadas por la finalidad de transparencia, límite que como hemos visto también es válido para los ciudadanos.

e) Un tema crucial es qué límites han de jugar en el acceso a los concejales a la información. La LBRL y el ROF no se refieren a ello, si bien permiten al Alcalde o Presidente denegar motivadamente las solicitudes. Esta indefinición legal acompañada de esta libertad de decisión de los Alcaldes o Presidentes colisiona desde luego con los principios elementales de nuestra Constitución (interdicción de la arbitrariedad, reserva de ley para la limitación de los derechos, necesidad de que los posibles límites establecidos por la ley tengan fundamento en preceptos constitucionales y sean proporcionados...). Al respecto, el catálogo de límites establecidos en la LTBG ha de entenderse vigente también en el acceso de los concejales. Pero cabe plantearse, bajo la enseña del principio que formulamos en la letra a), si respecto de éstos han de jugar de una forma más atenuada, en la medida en que la función política de los concejales conecta directamente con el art. 23 CE. En particular, el límite más habitual es el relativo al derecho a la intimidad y a la protección de datos, en los que como se dijo, y en síntesis, el principio más general es que cuando se trata de datos personales no especialmente protegidos hay que ponderar el perjuicio que supondría para el afectado su revelación y el interés público para la transparencia (ergo, para la participación y control ciudadanos, en este caso a través de sus representantes) y debe prevalecer, como regla general, cuando sea información directamente atinente a la organización, la actividad o el gasto público, como es el caso. Además, a diferencia de la LTBG y la LTA, que permiten al ciudadano difundir cualquier información que obtengan a través del ejercicio del derecho de acceso (es más, se potencia como vimos la publicidad activa por la propia Administración de toda información que haya sido facilitada por esta vía), la normativa local impone a los miembros de la Corporación el deber de guardar reserva 
en relación con las informaciones que se les faciliten para hacer posible el desarrollo de su función, singularmente de las que han de servir de antecedente para decisiones que aún se encuentren pendientes de adopción, así como para evitar la reproducción de la documentación que pueda serles facilitada, en original o copia, para su estudio. Todo ello lleva a concluir que la protección de datos no puede suponer una "excusa" para ocultar información relevante para el ejercicio de la función del concejal conectada con el art. $23 \mathrm{CE}^{41}$.

\footnotetext{
${ }^{41}$ En ese sentido, la propia jurisprudencia viene reconociendo el derecho de los concejales (a diferencia del común de los ciudadanos) a acceder a datos del padrón para poder ejercer su labor de control y crítica. Un tanto más restrictiva, como suele ocurrir, es la visión de la Agencia Española de Protección de Datos, que considera que en las transmisiones de información a los concejales hay una cesión de datos (lo que es discutible pues se trata de miembros de la propia corporación y no de terceras personas) y por ende cualquier transmisión debe estar justificada conforme al principio de proporcionalidad (así, en el Informe 0016/2013, en un caso de solicitud de un concejal del acceso a información sobre la identidad de las personas que tienen asignados teléfonos móviles corporativos así como el registro de llamadas entrantes y salientes, considera que la primera es proporcionada pero la segunda no).
} 